This item was submitted to Loughborough's Research Repository by the author.

Items in Figshare are protected by copyright, with all rights reserved, unless otherwise indicated.

\title{
On the dynamics of lubricated hypoid gears
}

PLEASE CITE THE PUBLISHED VERSION

http://dx.doi.org/10.1016/j.mechmachtheory.2011.08.012

\section{PUBLISHER}

(c) Elsevier

\section{VERSION}

AM (Accepted Manuscript)

\section{LICENCE}

CC BY-NC-ND 4.0

\section{REPOSITORY RECORD}

Karagiannis, loannis, Stephanos Theodossiades, and Homer Rahnejat. 2019. "On the Dynamics of Lubricated Hypoid Gears". figshare. https://hdl.handle.net/2134/13349. 
This item was submitted to Loughborough's Institutional Repository (https://dspace.lboro.ac.uk/) by the author and is made available under the following Creative Commons Licence conditions.

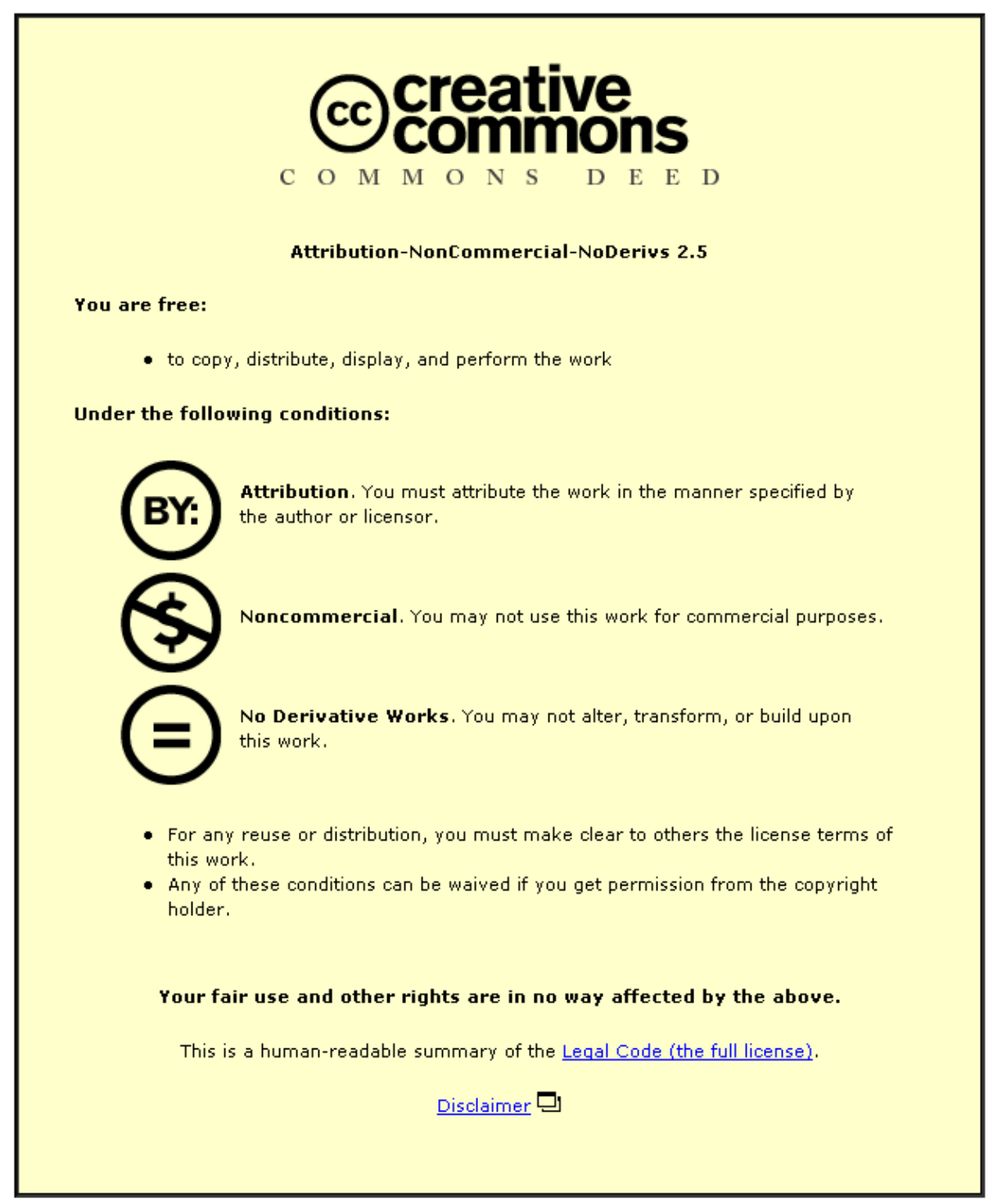

For the full text of this licence, please go to: http://creativecommons.org/licenses/by-nc-nd/2.5/ 


\title{
On the dynamics of lubricated hypoid gears
}

\author{
I. Karagiannis, S. Theodossiades ${ }^{1}$ and H. Rahnejat \\ Wolfson School of Mechanical \& Manufacturing Engineering, \\ Loughborough University, Loughborough, UK
}

${ }^{1}$ Corresponding Author: S.Theodossiades@lboro.ac.uk

Tel: + 44 (0) 1509227664 Fax: + 44 (0) 1509227648

\begin{abstract}
The torsional dynamics of a vehicle differential hypoid gear pair is investigated. The model comprises applied torque, representing transmitted engine power, including engine order vibration. A number of gear teeth pairs transmit the applied torque through their lubricated conjunctions. Tooth contact analysis (TCA) is used to obtain the appropriate geometrical, kinematic and meshing parameters. These enable the evaluation of contact loads, film thickness and friction for conjugate teeth pairs, which are subject to mixed thermo-elastohydrodynamic regime of lubrication. It is shown that the lubricant undergoes non-Newtonian shear in line with the Eyring regime of traction. The inclusion of combined thermal non-Newtonian shear and boundary interactions has not hitherto been reported for the tribo-dynamics of hypoid gear pairs. When rate of change of gear teeth contact radii is included in the analysis more complex system dynamics (loss of teeth contact) result, particularly at higher speeds. The stated features constitute the main contributions of the current work, which have not hitherto been reported in literature. It is also shown that teeth contact separation ensues when resonant conditions are noted. This is regarded as the main root cause of a noise and vibration phenomenon, known as axle whine.
\end{abstract}

\section{Keywords}

Hypoid gear pair, Thermo-elastohydrodynamics, non-Newtonian Eyring regime of traction, asperity interactions, axle whine phenomenon

\section{Introduction}

Gears have been studied extensively for a very long time, initially because of their inherent unreliability due to poor lubrication and, now in addition, as a noise and vibration concern. There are a multitude of reasons underlying gear vibration; including backlash and errors in the form and finish of mating gear teeth pairs, defined as kinematic transmission error. These errors and misalignment of gear pairs and their supporting shafts are important causes of vibration and noise, as well as poor lubrication, friction and wear. Therefore, besides studying the effect of machine and cutter tool settings to reduce mal-form and finish, the dynamic response of gear sets, when in situ, has also been extensively researched. The latter area is due to 
the effect of various system non-linearities. Consequently, an array of modelling techniques is used, depending on the conditions pertaining to a defined problem [1].

A significant number of models have been proposed to obtain the dynamic response of parallel axes gears in order to ascertain the extent of system stability and attainment of desired periodic motions. Implementation of lumped parameter models is a common practice, followed by analytical expressions for time varying parameters, such as for the meshing stiffness. The main source of non-linearity in these formulations is the presence of backlash, promoting impacts which can lead to impulsive actions and potential chaotic behaviour [2-10]. Similar analyses on crossed-axes gear sets have shown more complex responses. For example, hypoid gears, used in a wide range of applications, present complex meshing geometry. Consequently, there is a lack of analytical expressions to quantify the effect of their underlying governing parameters. Prior to the development of Tooth Contact Analysis (TCA) tools, experimental and empirical formulations were commonplace [11-12]. These early models precluded the exact meshing geometries. Instead, they were based on simplifications to the meshing force vector used in purely torsional dynamic analyses.

The first attempt to build a hypoid gear vibration model, based on exact geometry, was made by Cheng and Lim [13]. Generation of gear pair surfaces and the discretisation of the elliptical contact area resulted in the development of a threedegree of freedom (DOF) model. The significance of this approach was in relating the meshing parameters to the actual gear geometrical characteristics. Moreover, it allowed for the transmission of mesh load to the structural components of the differential unit [13]. A further study [14] included backlash non-linearity and timedependent meshing parameters, enabling the identification of resonant modes and, therefore, the study of the effect of load torque on system dynamics. Wang et al [15] focused on a hypoid gear pair, describing the dependence of meshing parameters' variation with the dynamic response of the system. An original two-DOF system was reduced to a single DOF and its dynamic response was computed using two different models. The first model only included the fundamental harmonics of the meshing parameters, whilst the second one imported their exact values. The generation of impact phenomenon was discussed, as well as the transition of system response from a periodic motion to a chaotic state with the variation of load torque and introduction of damping.

As already noted, friction generated in gearing systems is also an important area of investigation as this determines the efficiency of transmission and differential systems, as well as affecting their dynamic response. Confining oneself to some representative studies, it is important to note that gear teeth are often only partially lubricated as many fore-running contributions have shown [16-17]. This is known as mixed elastohydrodynamic regime of lubrication, where the mechanisms contributing to friction are viscous shear of a thin lubricant film and interaction of asperities on the contiguous surfaces with an insufficient film thickness. This is referred to as boundary friction and is prevalent in gear teeth interactions [18]. Vaishya and Singh [19-21] developed a dynamic model with viscous friction on gear flanks. Neglecting the effect of backlash and simplifying the derivation of coefficient of friction, they were able to perform a stability analysis for gear pairs using the Floquet theory [22]. Another study by $\mathrm{He}$ et al [23] concentrated on the effect of sliding friction upon the 
dynamic response of a gear set, while assuming empirical formulae for the coefficient of friction. Similar analyses were conducted for helical gears by Velex and Cahouet [24], Velex and Sainsot [25], as well as Kar and Mohanty [26]. The common approach in the above studies was the dependence of friction on the variation of length of line of contact. A method based on TCA was introduced by He et al [27] for modelling the bearing force on a twelve-DOF system.

For helical gear pairs, De la Cruz et al $[18,28]$ have reported models for a transaxle transmission system, where a combined tribological and vibration analysis was carried out. In their model the unselected loose gear teeth pairs were modelled as lightly loaded thermo-hydrodynamic conjunctions with viscous friction, whilst the engaged gear pairs were subject to a mixed thermo-elastohydrodynamic regime of lubrication. They showed that thermal effects in the gear teeth pair contacts significantly reduce lubricant film thickness. An analytic solution to energy equation for the determination of lubricant temperature in the contact was used [29], whilst Grubin's [30] analytical solution was employed for the loaded elastohydrodynamic conjunctions of teeth pairs of engaged gears. This provided a quasi-steady solution, one which does not take into account the enhanced load carrying capacity of the teeth pair contact conjunctions due to any lubricant squeeze film effect. The approach, including the squeeze film effect was advocated by Rahnejat [31-32] subject to various regimes of lubrication, including isothermal elastohydrodynamic conditions. It was shown that the lubricant film behaviour is frequency dependent. An extension of this work by Mehdigoli et al [33], representing a pair of gears as wavy surfaced discs showed that fluid film lubrication possesses insignificant damping under elastohydrodynamic conditions, which verified the earlier experimental findings of Johnson and Gray [34]. However, these studies did not include the effects of viscous or boundary friction, nor shear thinning of the lubricant in a thermal contact. Another numerical quasi-steady mixed isothermal EHL solution, combined with torsional vibration of gear pairs, was highlighted by Li and Kahraman [35] for line contact condition, applicable to spur gears and as an approximation for helical gears.

A few tribodynamics' studies have been reported for hypoid gears; including the effects of viscous and boundary friction. Geometrical complexities of hypoid gears in mesh and the need to determine the instantaneous area of contact necessitates use of numerical methods, rather than the simpler analytical approaches. The sliding velocities of mating gear teeth pairs and the sense of application of friction cannot be calculated analytically due to the time varying nature of the mesh vector. As already noted, an approach to obtain the friction vector has been reported by Cheng and Lim [14], based upon a simulated geometry, whereas the derivation of kinematic contact properties was described by $\mathrm{Xu}$ and Kahraman [36]. Authors validated the various empirical formulae for representation of coefficient of friction against an elastohydrodynamic lubrication model. Good agreement with experimental results was shown and a formula describing the results was obtained.

A number of other researchers have also focused on transient EHL representation of the contact zone between the gear flanks. These include the works reported by Holmes et al [37-39], who treated the contact zone of pairs of hypoid gear teeth as a point contact problem, which is a reasonable approximation. Isothermal solution of gear lubrication problem has received more attention than those including thermal effects. An investigation of thermal effects was also reported by Handschuh and 
Kircher [40], who calculated the temperature distribution inside the contact zone due to heat generation.

In this work, TCA is used to determine the kinematic and geometrical properties of the hypoid gears, necessary for the thermo-elastohydrodynamic analysis. The rate of change of the teeth contact radii has been considered in the analysis. This is the main contribution of the current work compared with those previously published. It reveals a more pronounced dynamics, characterised by teeth separation near 1:1 resonant conditions. Asperity contribution to friction is also included by characterisation of the tooth flank topography and use of Greenwood and Tripp [41] friction model. Therefore, the analysis in this paper is that of a quasi-steady mixed thermo-elastohydrodynamics of hypoid gear teeth pairs, and its effect upon the dynamics of a hypoid gear pair of a vehicle differential unit. Such an approach has not hitherto been reported in literature.

\section{Methodology}

\subsection{Gear Dynamics}

The primary objectives of the current analysis are prediction of the vibration response of hypoid gear pairs in automotive differentials and their transmission efficiency. Both these are affected by the friction generated in the gear teeth pair lubricated conjunctions. A lumped parameter two-DOF dynamic model similar to that proposed by Wang et al [15] is developed. The core model in figure 1 is based on the fundamental gear pair models as in other fore-running contributions [2-9]. It takes into account only the torsional motions of the pinion and its conjugate gear wheel, where meshing takes place along the line of action shown in Figure 1.

The equations of motion with respect to the angular rotations $\varphi_{p}$ and $\varphi_{g}$ of the pinion and gear wheel, respectively, can be written as:

$$
\begin{aligned}
& I_{p} \ddot{\varphi}_{p}+R_{p} c_{m} \dot{x}+R_{p} k_{m}(t) f(x)=T_{p} \\
& I_{g} \ddot{\varphi}_{g}-R_{g} c_{m} \dot{x}-R_{g} k_{m}(t) f(x)=-T_{g}
\end{aligned}
$$

where the terms $c_{m}(\dot{x})$ and $k_{m}(t) f(x)$ express the overall damping and elastic forces developed during mesh. The meshing stiffness is represented by the term $k_{m}(t)$ whereas $c_{m}$ is the mesh damping coefficient. The variable $x$ is a function of angles $\varphi_{p}(t)$ and $\varphi_{g}(t)$, the radii $R_{p}$ and $R_{g}$ and the static transmission error under no load condition, $e(t)$, thus:

$$
x(t)=\int_{t_{0}}^{t} R_{p} \dot{\varphi}_{p}(t) d t-\int_{t_{0}}^{t} R_{g} \dot{\varphi}_{g}(t) d t-e(t)
$$




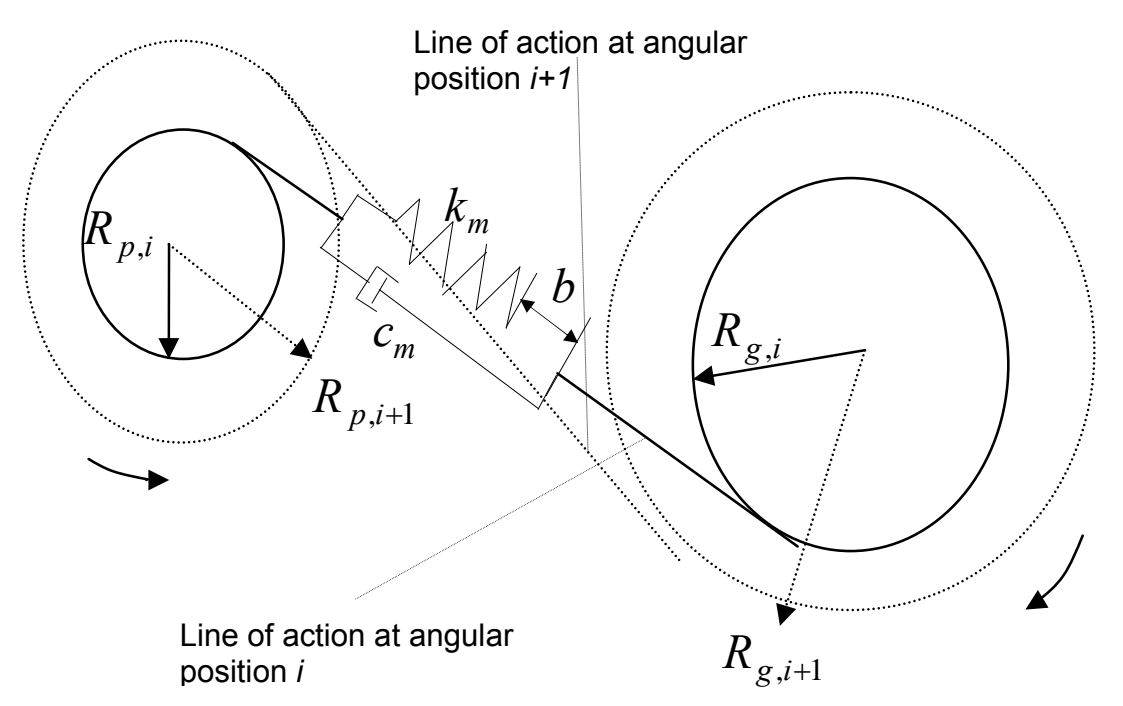

Figure 1: The hypoid gear pair mesh model

Function $f(x)$ defines the effect of backlash non-linearity in terms of approach and separation of teeth pairs within their nominal backlash. If the quantity $2 b$ is the total gear backlash, then:

$$
f(x)= \begin{cases}x-b, & x \geq b \\ 0, & -b<x<b \\ x+b, & x \leq-b\end{cases}
$$

The variation of meshing stiffness with respect to time is crucial for the dynamic response of the system and can be calculated through TCA [15, 26, 42]. Due to time variation of the meshing vector, affected by the hypoid gear geometry, the radii $R_{p}$ and $R_{g}$ also follow the same trend. In the case of a parallel axes gear set, these are the base radii of the pinion and the gear wheel respectively. This variation explains the integral form of the dynamic transmission error in equation (3). TCA is also involved in the definition of $R_{p}$ and $R_{g}$ [13-15]. The free body diagram of the examined system is shown in Figure 2. The coordinate systems used in the determination of the contact geometric parameters are shown in Figure 3.

It is noteworthy that some previous studies of parallel axis gear pairs [2-7] take the common simplifying assumption that the rate of change of the radii $R_{p}$ and $R_{g}$ is insignificant through mesh, thus: $\dot{R}_{p}=\dot{R}_{g}=\ddot{R}_{p}=\ddot{R}_{g} \cong 0$. Therefore, system dynamics may be reduced to an equivalent single DOF torsional system. A similar technique was also used in [15] for the case of hypoid gears. Whilst this simplifying assumption may be upheld at low rotational speeds, in the case of high speed gearing systems the aforementioned derivatives can become significant. Hence, the current analysis includes the rate of change of these radii. This is also the reason behind the definition of the dynamic transmission error in an integral form in this work - equation (3) - contrary to the previous studies, for example in [15]. Therefore, the current method essentially yields in an irreducible two-DOF system. 


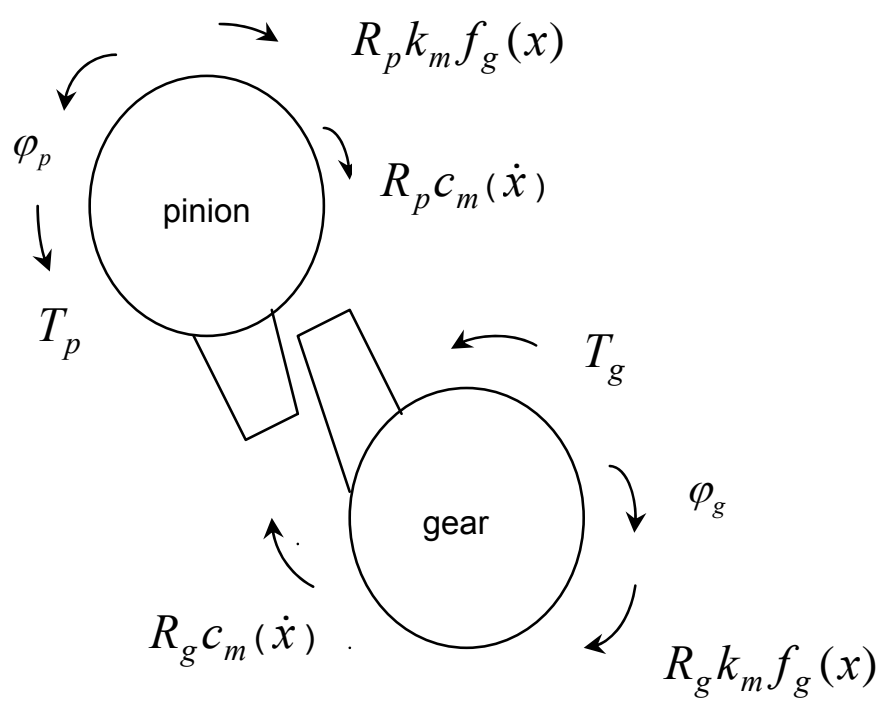

Figure 2: Free body diagram of the hypoid gear pair

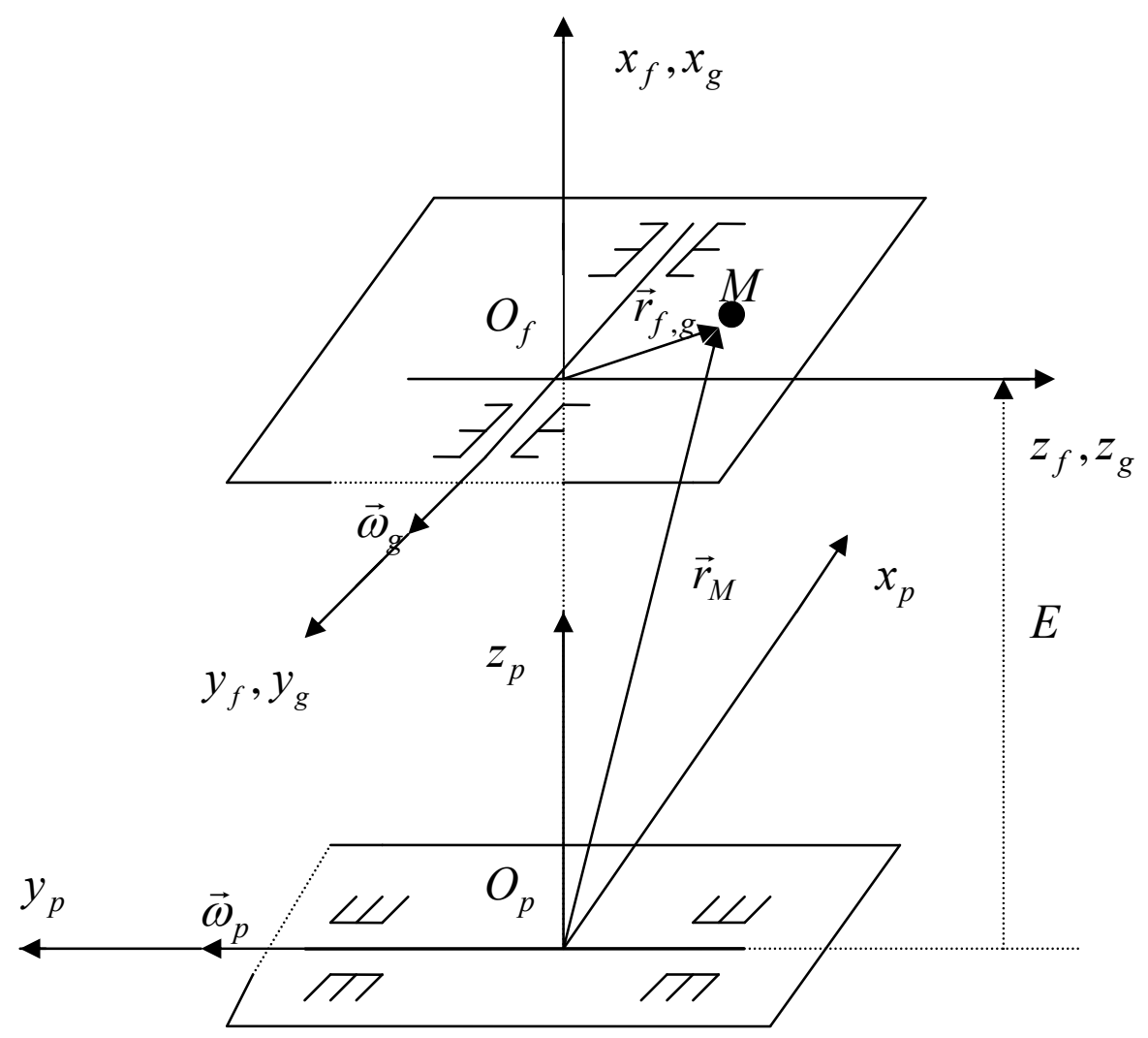

Figure 3: Coordinate systems used in TCA

\subsection{Inclusion of friction torque}

During meshing, the contacting teeth pairs undergo combined rolling and sliding motions. Velex and Cahouet [24] note that sliding is the main source of friction, thus responsible for the power losses in helical gears, particularly at low to medium speeds. The underlying tribological reason is the reduced lubricant film thickness at lower surface velocities. This also results in higher friction and consequently 
generated heat. In hypoid gears in particular, because of the axial offset, increased longitudinal sliding occurs [43]. For the above reasons, one may surmise that when considering hypoid gears, the sliding effect dominates any pure rolling contact, which contributes little to friction in lubricated contacts [29].

It has been shown that sliding friction in the gear meshing problem can act as an external source of excitation, with a periodic nature and as a non-linear coupling agent, as well as a significant source of energy dissipation [19]. It is, therefore, obvious that friction is coupled in a non-linear manner with the dynamic behaviour of a gear pair [19-20]. Therefore, an accurate prediction of system dynamics requires representative description of friction.

Based on the above consideration the equations of motion in presence of friction are altered to:

$$
\begin{aligned}
& I_{p} \ddot{\varphi}_{p}+R_{p} c_{m} \dot{x}+R_{p} k_{m}(t) f(x)=T_{p}+T_{f r, p} \\
& I_{g} \ddot{\varphi}_{g}-R_{g} c_{m} \dot{x}-R_{g} k_{m}(t) f(x)=-T_{g}+T_{f r, g}
\end{aligned}
$$

The above equations have the same stiffness and damping properties as those in (1) and (2). The terms $T_{f r, p}$ and $T_{f r, g}$ represent the induced frictional torques at the pinion and gear wheel, respectively. The sense of friction torques depends on the direction of generated friction. This means that the torque exerted through friction can either assist or resist the motion of the system [26-27].

The calculation of friction torque is a two step process. The first step is to determine the sense of friction. This opposes the direction of sliding. The geometrical complexity of the system necessitates the implementation of TCA [42]. The second step involves the definition of the underlying mechanism of friction. In the case of viscous shear this is inversely proportional to the lubricant film thickness [29]. Of course, as already noted, there is also boundary friction due to asperity interactions on the contiguous surfaces when the lubricant film thickness is insufficient to guard against their direct interactions.

For the case of spur [19-20] and helical [26-27] gears, the direction of friction and consequently its moment arm are given by analytical expressions as the direction of sliding is always known. For hypoid gears, such expressions do not exist, hence numerical methods are used. A method for obtaining the kinematic properties of hypoid gears was proposed by Xu and Kahraman [36]. This approach evaluates the surface velocities of the contacting surfaces with the aid of Rodrigues' formula, using the angular velocities and the surface curvatures. Nevertheless, it is noteworthy that in their analysis a line contact is implied rather than a more realistic elliptical point contact.

\subsection{Elastohydrodynamic conjunctions}

\subsubsection{Contact kinematics}

In this paper, the kinematic properties are derived with the aid of CALYX [42]. This is a TCA piece of software, simulating quasi-statically the meshing of a hypoid gear 
teeth pair. At each simulation time step, CALYX yields the curvatures and contact properties for a set of points which are assumed to lie along the major axis of the Hertzian elastostatic contact ellipse. The orientation of the elliptical contact area, as well as the radii of curvature along its semi-major and semi-minor axes can be defined by the corresponding data for an assumed equivalent single point of contact. In gear teeth pairs the lubricant entrainment into the contact usually occurs at an angle to the minor axis of the contact ellipse. If $\vec{r}=\left[\begin{array}{lll}r_{x} & r_{y} & r_{z}\end{array}\right]^{T}$ denotes the position vector at the mesh point and $\vec{\xi}=\left[\begin{array}{lll}\xi_{x} & \xi_{y} & \xi_{z}\end{array}\right]^{T}$ is the unit vector along the sliding direction, the surface velocity of the pinion along this direction is obtained as:

$$
v_{s}=\vec{\xi}^{\left(S_{p}\right)} \cdot\left(\vec{\omega}_{p}^{\left(S_{p}\right)} \times \vec{r}^{\left(S_{p}\right)}\right)=\omega_{p} \vec{\xi}_{p}^{\left(S_{p}\right)} \cdot\left(\vec{j}_{p} \times \vec{r}^{\left(S_{p}\right)}\right)=\dot{\varphi}_{p} r_{f r, p}
$$

where $\vec{\omega}_{p}=\left[\begin{array}{lll}0 & \omega_{p} & 0\end{array}\right]^{T}$ is the pinion angular velocity and $\vec{j}_{p}$ is the unit vector along the rotational direction $y_{p}$ of the pinion. All vectors in equation (7) are defined with respect to a coordinate system $S_{p}\left(x_{p}, y_{p}, z_{p}\right)$ fixed at the centre of the pinion. It is then clear that:

$$
r_{f r, p}=\vec{\xi}^{\left(S_{p}\right)} \cdot\left(\vec{j}_{p} \times \vec{r}^{\left(S_{p}\right)}\right)=\xi_{x}{ }^{\left(S_{p}\right)} r_{z}{ }^{\left(S_{p}\right)}-\xi_{z}{ }^{\left(S_{p}\right)} r_{x}{ }^{\left(S_{p}\right)}
$$

A similar expression also exists for the gear wheel, if all vectors are expressed with a coordinate system $S_{g}\left(x_{g}, y_{g}, z_{g}\right)$, fixed at the centre of the gear wheel:

$$
r_{f r, g}=\vec{\xi}^{\left(S_{g}\right)} \cdot\left(\vec{j}_{g} \times \vec{r}^{\left(S_{g}\right)}\right)=\xi_{x}{ }^{\left(S_{g}\right)} r_{z}{ }^{\left(S_{g}\right)}-\xi_{z}{ }^{\left(S_{g}\right)} r_{x}{ }^{\left(S_{g}\right)}
$$

Radii $r_{f r, p}$ and $r_{f r, g}$ represent the moment arms for friction torque applied to the pinion and gear wheel, respectively. When multiplied by the angular velocity they yield the instantaneous surface velocities of a meshing teeth pair. As shown by Cheng and Lim [14], these are related to the tangential friction component at the contact point in the sliding direction $\vec{\xi}$. They depend on the position of the contact point and the orientation of the contact ellipse. This information is derived from CALYX [42], based on a numerical representation of the gear pair geometry.

\subsubsection{Elastohydrodynamic lubricant film}

The contact between a pair of hypoid gears is subjected to elastohydrodynamic regime of lubrication with the lubricant viscosity altering with generated pressure and temperature. A numerical solution for the derivation of the tribological properties requires a significant computation time [36-39], taking into account the multiple teeth pairs in simultaneous contact. Therefore, the solution for film thickness is obtained in this work through use of Grubin's extrapolated oil film thickness formula [30]. Therefore, for an elliptical point contact, the film thickness $h_{0}$ in the parallel region of an elastohydrodynamic conjunction is defined as: 


$$
\frac{h_{0}}{R_{z x}}=1.212\left(\frac{\alpha \eta_{e} U}{R_{z x}}\right)^{3 / 4}\left(\frac{W}{E^{*} R_{z x}{ }^{2}}\right)^{-1 / 12} \psi^{2 / 3}
$$

The effect of gear geometry is described by the equivalent radius of curvature along the sliding direction $R_{z x}$. Parameter $\psi$ is a correction factor appended to the original Grubin's formula by Gohar [17] to take into account the side leakage of lubricant from an elliptical conjunction:

$$
\psi=\left(1+\frac{2}{3} \frac{R_{z x}}{R_{z y}}\right)^{-1}
$$

The required input quantities are obtained by CALYX with respect to the pinion angle. After an interpolation scheme (expansion in terms of Fourier series), they are used in the numerical code as a function of the pinion angle.

The reduced elastic modulus $E^{*}$ and the equivalent radii of curvature $R_{z x}, R_{z y}$ along the $x$ and $y$ axes of the contact ellipse are described in reference [17].

\subsubsection{Contact load and speed of entraining motion}

Under the quasi-steady conditions taken into account in this work, the mechanism of lubricant film formation is through entraining motion of the lubricant into gear teeth pair conjunctions. The speed of entraining motion $U$ is obtained as [20-21]:

$$
U=\frac{1}{2}\left(\dot{\varphi}_{g} r_{f r, g}+\dot{\varphi}_{p} r_{f r, p}\right)
$$

The geometric and kinematic parameters at the contact ellipse are depicted in Figure 4.

The contact load per teeth pair is also a function of the dynamic response of the system. However, its distribution among teeth pairs in simultaneous contact is defined quasi-statically. A load distribution factor is calculated as a function of the pinion angle for all such contacts. This is the ratio of the applied load $W_{i}$ on a given flank under consideration to the total transmitted load $W_{\text {total }}$ :

$$
l f=\frac{W_{i}}{W_{\text {total }}}
$$

A similar technique was followed for spur and helical gears in [19, 27]. With an interpolation technique this parameter is inserted into the dynamic model, defining the meshing load on each flank under consideration. In this manner, the dynamic parameters comprise two sets; one obtained through numerical integration of equations of motion and the other through quasi-static contact analysis. This is the 
most efficient way to account for the geometrical complexities posed by the hypoid gear transmissions.

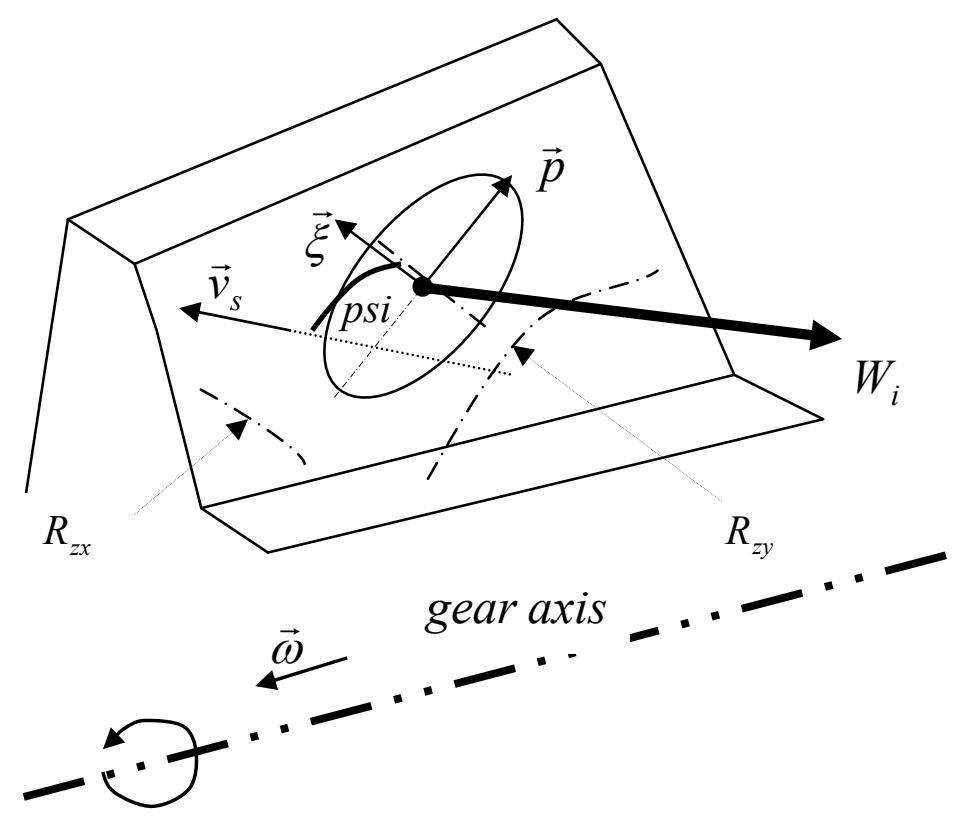

Figure 4: Geometric and kinematic properties at contact ellipse

\subsubsection{Thermal Analysis}

Thin films formed in gear teeth pair conjunctions are often subject to thermal nonNewtonian shear. This behaviour is determined by a limiting shear stress, first defined by Eyring [44]. Johnson and Greenwood [45] showed that in the flat parallel region of a thin elastohydrodynamic film the dominant mechanism giving rise to contact temperature is viscous shear at the effective viscosity of the lubricant:

$$
\eta_{e} \frac{\partial u}{\partial z}=\eta \dot{\gamma}=\tau_{0} \sinh \left(\frac{\tau}{\tau_{0}}\right)=\tau^{*}
$$

Because of the thinness of the film, any variation in the Eyring shear stress $\tau_{0}$ across the film may be neglected. The heat generated through shear is conducted away through the bounding surfaces in contact [29, 45], thus the energy equation becomes:

$$
\tau \frac{\partial u}{\partial z}=\frac{\tau \tau^{*}}{\eta_{e}}=-K \frac{\partial^{2} \theta}{\partial z^{2}}
$$

Lubricant viscosity is dependent on pressure $p$ and temperature $\theta$. Using Houpert's equation [46]:

$$
\eta_{e}=\eta_{0} \exp \left(a^{*} p\right)
$$


where:

$$
\alpha^{*} p=\left[\ln \left(\eta_{0}\right)+9.67\right]\left\{\left(\frac{\Theta_{e}-138}{\Theta_{0}-138}\right)^{-S_{0}}\left(1+5.1^{*} 10^{-9} p\right)^{Z}-1\right\}
$$

and $\Theta_{0}=\theta_{0}+273, \Theta_{e}=\theta_{e}+273$.

In the above equations of state, $\eta_{0}$ is the atmospheric lubricant dynamic viscosity at a reference temperature. In the current analysis the effects of both pressure and temperature are taken into account in order to determine the effective lubricant viscosity in the contact. However, for evaluation of film thickness from equation (10), the effective viscosity is only due to the effective temperature, not pressure as the latter is implicit in Grubin's original assumption. Therefore, one needs to obtain the effective temperature $\theta_{e}$ and the corresponding effective viscosity $\eta_{e}$.

An analytical solution to equation (15) can be made when an average value for lubricant temperature in the contact is assumed [29] (effective temperature $\theta_{e}$ ), using average values for $\left(\eta, \tau_{0}, \beta^{*}, K\right)$. Furthermore, both surfaces are assumed to be at the same temperature and act as perfect conductors of heat. This implies that their temperature would remain the same as that of the bulk oil inlet temperature into the conjunction. They would conduct away equal portions of heat generated in the contact. Therefore, Johnson and Greenwood [45] derived the traction behaviour of such a thin lubricant film as a Eyring fluid:

$$
\frac{\tau}{\tau_{0}}=\frac{4 A^{2} X^{*} X}{\Delta U^{*}}
$$

where: $\Delta U^{*}, A, X$ and $X$ are provided in reference [45] and the sliding velocity is given by:

$$
\Delta U=\dot{\varphi}_{g} r_{f r, g}-\dot{\varphi}_{p} r_{f r, p}
$$

Using equation (14) and employing equations (16) and (18), yields [17, 29]:

$$
\sinh \left(\frac{4 A^{2} X^{*} X}{\Delta U^{*}}\right)=\Delta U^{*} \frac{X^{*}}{X}
$$

On the grounds that sliding velocity $\Delta U$ is obtained from contact kinematics (equation (19)), equation (20) can be solved in an iterative manner, using an initial guess value for the temperature rise $\Delta \theta=\theta_{e}-\theta_{0}$. This yields the effective temperature and viscosity. Note that the film thickness is adjusted for temperature only, $\eta_{e^{\prime}}=\eta(\theta)$ for equation (10).

The mean Hertzian pressure value in the contact zone is [29]: 


$$
p_{\text {mean }}=\frac{2}{3}\left\{\frac{6 W E^{2}}{\pi^{3} \sqrt{R_{z x} R_{z y}}}\right\}^{1 / 3}
$$

The surfaces of gear flanks are rough and the thickness of lubricant film may be insufficient to guard against asperity pair interactions. The typical gear teeth composite root mean square roughness is $R_{q}=0.5 \mu m$ (for lapped finished gears). Then, the Stribeck oil film parameter $\lambda=\frac{h}{R_{q}}$ can be obtained at any instant of time for each pair of interacting gear pair flanks. The surface roughness of gear flanks were assumed to be represented by a Gaussian distribution according to the roughness parameter $\zeta \kappa \sigma$. Then, the asperity area of contact is obtained as [47]:

$$
A_{a}=\pi^{2}(\zeta \kappa \sigma)^{2} A F_{2}(\lambda)
$$

where $F_{2}(\lambda)$ is defined in reference [47].

The contribution due to viscous friction is obtained as:

$$
F_{v}=\tau\left(A-A_{a}\right)
$$

Where, the overall contact area is that of an elliptical Hertzian form: $A=\pi\left[\frac{3 W \sqrt{R_{z x} R_{z y}}}{4 E^{*}}\right]^{2 / 3}$. The boundary friction is obtained as in [41]:

$$
F_{b}=\tau_{0} A_{a}+m P_{a}
$$

In this equation $m$ is the pressure coefficient of the boundary shear strength $(0.17$ for steel on steel contact) [47]. The overall friction force is the sum of these two individual components of friction: $F_{v}+F_{b}$. The coefficient of friction $\mu$ is defined as the quotient of the total friction force at each flank to the corresponding dynamic mesh force: $\mu=\frac{F_{v}+F_{b}}{W}$

Note that any temperature rise in the contact due to localised flash temperature of asperity pair interactions is assumed to have a negligible effect on the bulk lubricant effective viscosity.

A comment should be made with regard to the sense of friction force. The sign of friction force (and corresponding torque) is governed by the sign of the relative sliding velocity $[21,26]$. If the latter is negative, friction opposes the pinion motion and assists the motion of the gear if the situation is reversed for the case of positive sliding velocity. Nevertheless, even though the friction torque on a pinion flank during an instant of the meshing cycle might be positive, the total friction torque exerted by 
all teeth pairs in contact, is always negative. The opposite applies for the gear member. The energy deficit induced by the generation of friction can be calculated from the algebraic sum of the power incurred from the frictional moments:

$$
P_{\text {deficit }}=\dot{\theta}_{p} \cdot \sum_{i} \vec{r}_{f r, p i} \times \vec{F}_{f r, p i}+\dot{\theta}_{g} \cdot \sum_{i} \vec{r}_{f r, g i} \times \vec{F}_{f r, g i}
$$

\section{Results and discussion}

Figure 5 is the flow chart of the computational procedure used. At the outset, a quasi-static TCA is undertaken using CALYX [42]. This is in order to determine the contact parameters required for the solution of equations of motion. The contact pattern is obtained, taking into account the localised contact teeth deflections as well as the global deflection of the overall tooth shape. If a change in the external torque loading conditions is made, then a new analysis should be conducted. This is because the contact pattern alters with the applied external load. The total mesh force and its direction are calculated by summation of the load distribution given by CALYX, taking into account all the flanks in simultaneous contact. Additionally, the line of action of the mesh force is obtained by equating the total moment of the load distribution with the moment arising from the total contact forces. The locus of those points yields the line of action of the mesh load.

All the required data are expressed as Fourier series functions with respect to the pinion angle. The meshing stiffness, $k_{m}$ and the curvature radii of contact, $R_{p}$ and $R_{g}$ are periodic functions of the gear meshing frequency, $\omega_{\text {mesh }}$. Neglecting any toothto-tooth variations, the fundamental period is $\theta_{T}=2 \pi / N$ (in angular form), where $N$ is the number of pinion teeth [48]. For instance, the pinion contact radius $R_{p}$ can be expressed in a Fourier series with respect to the pinion angular position $\varphi_{p}$ as:

$$
R_{p}\left(\theta_{p}\right)=R_{p 0}+\sum_{i=1}^{\infty}\left[R_{p c i} \cos \left(i N \varphi_{p}\right)+R_{p s i} \sin \left(i N \varphi_{p}\right)\right]
$$

On the other hand, the principal radii of curvature of contact $R_{z x}$ and $R_{z y}$, the friction moment arms $r_{f r, p}$ and $r_{f r, g}$, as well as the load distribution factor $I f$ are all functions of the frequency $\omega_{f}=\omega_{\text {mesh }} / \varepsilon$, where $\varepsilon$ is the gear contact ratio. This is because the above quantities depend on the meshing sequence for each individual flank. For example, referring to flank (I):

$$
r_{f r, p}^{(I)}\left(\varphi_{p}\right)=r_{f r, p 0}+\sum_{i=1}^{\infty}\left[r_{f r, p c i} \cos \left(i \frac{N}{\varepsilon} \varphi_{p}\right)+r_{f r, p s i} \sin \left(i \frac{N}{\varepsilon} \varphi_{p}\right)\right]
$$




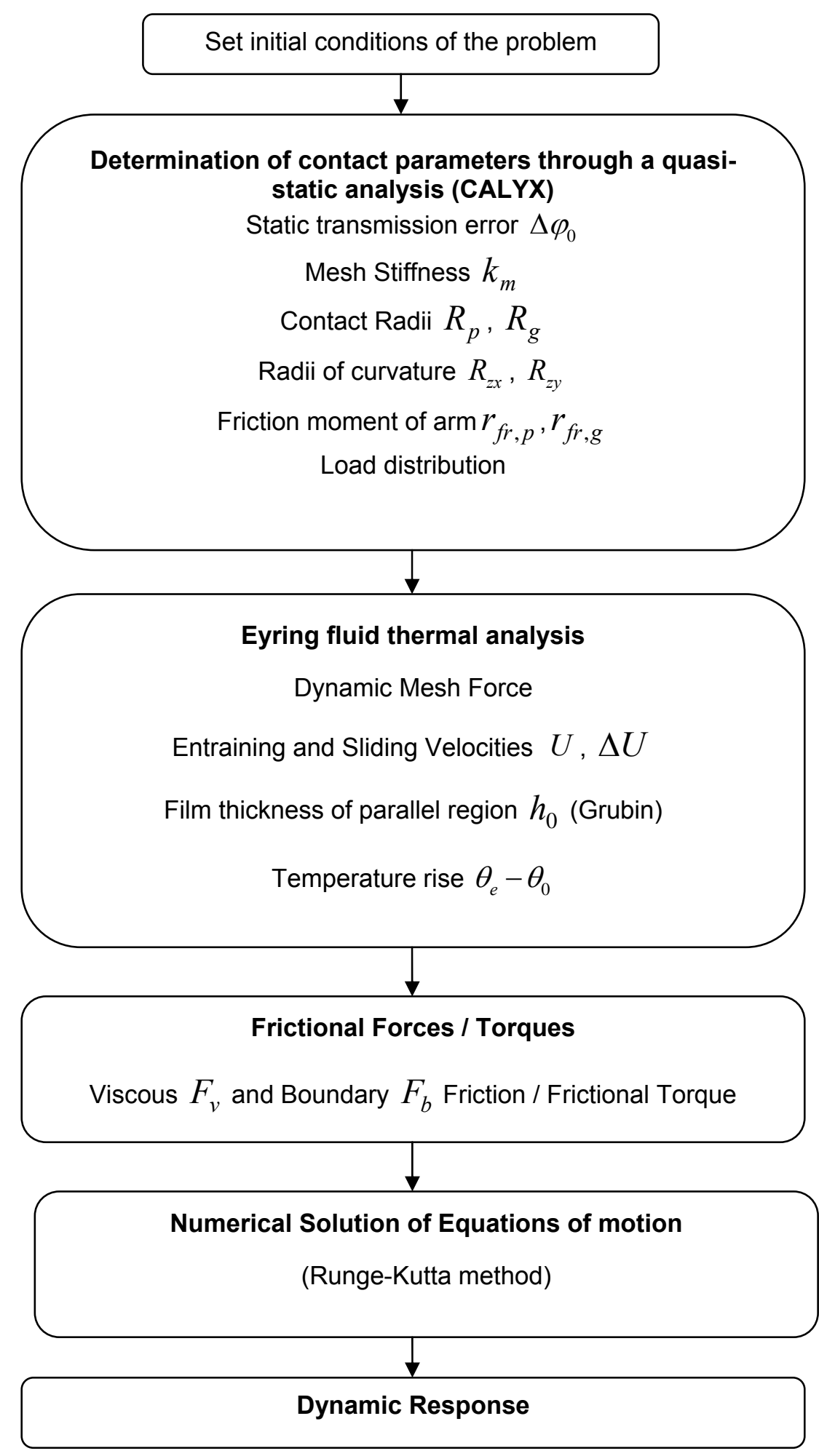

Figure 5: Computational flowchart

In the hypoid gear set considered in the current study, the maximum number of teeth pairs in simultaneous contact is three. Therefore, three functions similar to equation (27) should be defined. There will be an angular phase difference equal to the meshing period $\theta_{T}$ between these consecutive flanks. Hence: 


$$
\begin{aligned}
& r_{f r, p}^{(I I)}\left(\varphi_{p}\right)=r_{f r, p}^{(I)}\left(\varphi_{p}+\theta_{T}\right) \\
& r_{f r, p}^{(I I I)}\left(\varphi_{p}\right)=r_{f r, p}^{(I)}\left(\varphi_{p}-\theta_{T}\right)
\end{aligned}
$$

This means that flank (II) leads the flank (I), whilst flank (III) trails behind flank (I). The other sets of contact parameters are defined in a similar manner.

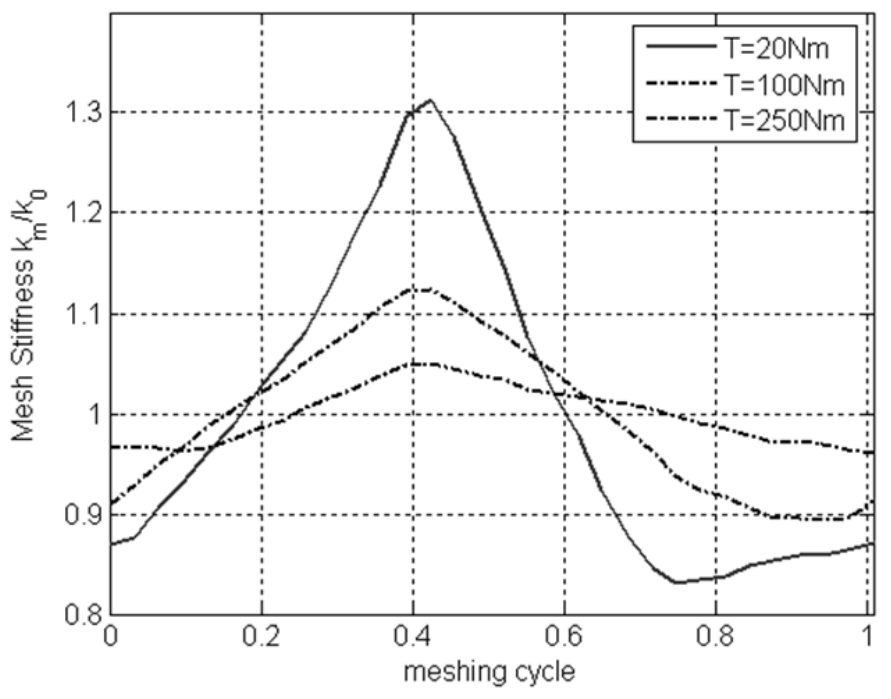

(a)

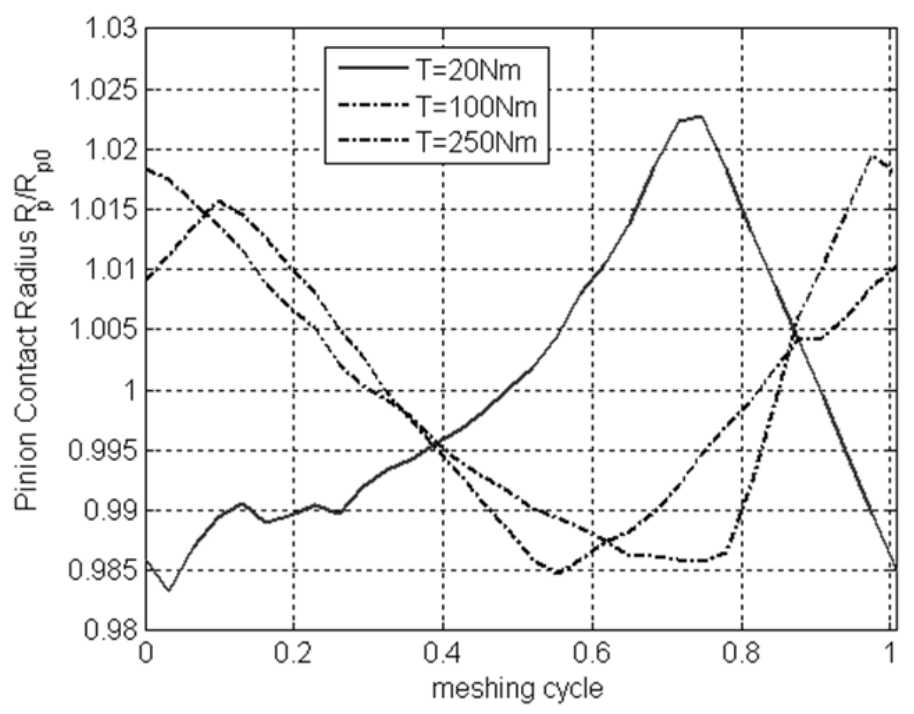

(b) 


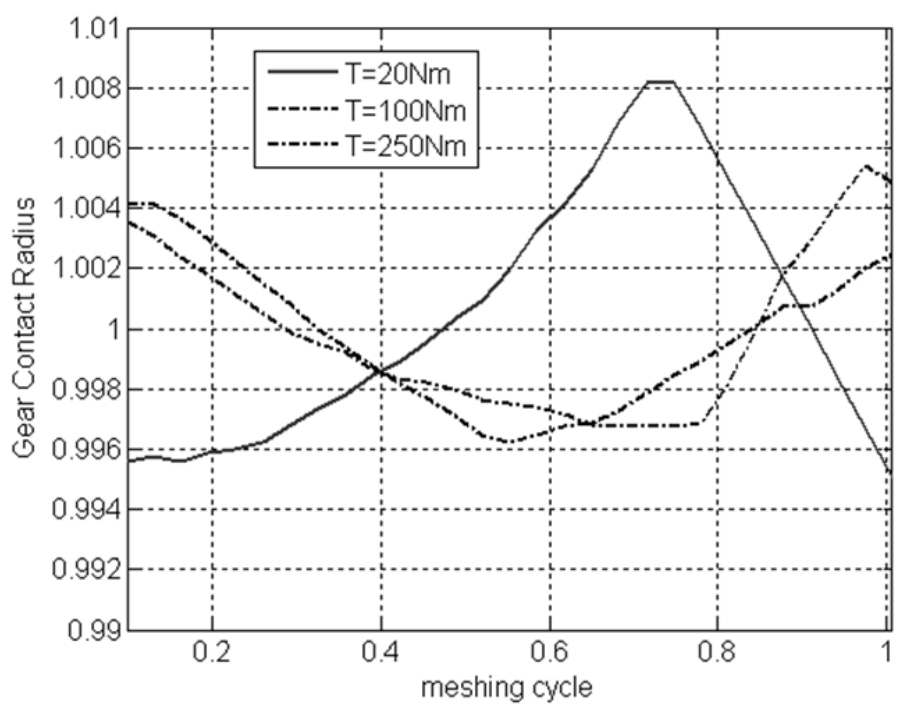

Figure 6: Dimensionless mesh parameters with respect to pinion angular rotation: (a) Mesh Stiffness $\hat{k}_{m}$, (b) Pinion contact radius $\hat{R}_{p}$, (c) Gear contact radius $\hat{R}_{g}$. $\longrightarrow T_{p}=20 \mathrm{Nm},----T_{p}=50 \mathrm{Nm}, \cdots \cdots \cdots \cdots \cdot T_{p}=100 \mathrm{Nm},-\cdot-\cdot-T_{p}=250 \mathrm{Nm}$

Figure 6 is a representation of the dimensionless stiffness and contact radii with respect to the instantaneous pinion angle. The mean values of $\mathrm{k}_{0}, \mathrm{R}_{\mathrm{p} 0}$ and $\mathrm{R}_{\mathrm{g} 0}$ have been used for non-dimensionalistion.

The geometric characteristics of the hypoid gear pair under consideration are listed in Table 1 (CALYX [42]). The gear pair normal backlash is $150 \mu \mathrm{m}$, corresponding to a typical automotive differential hypoid gear set. Previous studies on the dynamics of hypoid gear pairs have shown that loss of contact and flank separation can occur over some frequency range [15], depending on the meshing parameters and system excitation. The current study addresses the behaviour of the system within and away from such resonant region, which is defined as [3, 7 and 14]:

$$
\omega_{n}=\left(\frac{k_{0}}{m_{e q}}\right)^{1 / 2}=\left(\frac{k_{0}}{\frac{I_{p} I_{g}}{I_{p} R_{g 0}^{2}+I_{g} R_{p 0}^{2}}}\right)^{1 / 2}
$$

In the above expression, the denominator $m_{e q}$ corresponds to the equivalent mass of the system, where the mean values of meshing stiffness and contact radii are used. Despite the fact that these quantities vary with the pinion angular position, the above equation provides a reasonable approximation of the torsional natural frequency. 
Table 1: Gear pair parameters and machine/cutter settings (Gleason face hobbed gear set)

\begin{tabular}{ll}
\hline Pinion parameters: & \\
\hline Number of pinion teeth & 13 \\
Pinion face width $(\mathrm{mm})$ & 33.851 \\
Pinion face angle $(\mathrm{deg})$ & 29.056 \\
Pinion pitch angle $(\mathrm{deg})$ & 29.056 \\
Pinion root angle $(\mathrm{deg})$ & 29.056 \\
Pinion spiral angle $(\mathrm{deg})$ & 45.989 \\
Pinion pitch apex $(\mathrm{mm})$ & -9.085 \\
Pinion face apex $(\mathrm{mm})$ & 1.368 \\
Pinion Outer cone distance $(\mathrm{mm})$ & 83.084 \\
Pinion offset $(\mathrm{mm})$ & 24.0000028 \\
Pinion hand & Right
\end{tabular}

\begin{tabular}{ll}
\hline Gear parameters: & \\
\hline Number of gear teeth & 36 \\
Gear face width (mm) & 29.999 \\
Gear face angle (deg) & 59.653 \\
Gear pitch angle (deg) & 59.653 \\
Gear root angle (deg) & 59.653 \\
Gear spiral angle $(\mathrm{deg})$ & 27.601 \\
Gear pitch apex $(\mathrm{mm})$ & 8.987 \\
Gear face apex $(\mathrm{mm})$ & 10.948 \\
Gear Outer cone distance $(\mathrm{mm})$ & 95.598 \\
Gear offset $(\mathrm{mm})$ & 24
\end{tabular}

\begin{tabular}{ll}
\hline Pinion machine and cutter parameters: & \\
\hline Inside cutter blade angle (IB) (deg) & 21.529 \\
Outside cutter blade angle (OB) (deg) & 16.743 \\
Machine center to back (mm) & -0.288 \\
Basic swivel angle (deg) & -32.865 \\
Basic cradle angle (deg) & 64.433 \\
Tilt angle & 31.736 \\
Sliding base (mm) & 20.647 \\
Ratio of roll & 2.762 \\
Blank offset (mm) & 23.908 \\
Machine root angle (deg) & 0.202 \\
Cutter point radius (mm) & 63.743 \\
Radial setting (mm) & 86.983 \\
& \\
\hline Gear machine and cutter parameters: & 59.653 \\
\hline Machine root angle (deg) & 7.026 \\
Machine center to back (mm) & 66.650 \\
Horizontal setting (mm) & 62.642 \\
Vertical setting (mm) & 22.436 \\
Inside cutter blade angle (deg) & 15.815 \\
Outside cutter blade angle (deg) & 64.185 \\
Cutter point radius (mm) &
\end{tabular}

The main source of excitation in hypoid transmissions is the static transmission error, which appears because of geometric imperfections and contact misalignments, but is also affected by design specification for optimised response under load transfer [12, 
49]. Its variation during a meshing cycle can be derived either experimentally [50] or through TCA [42]. Figure 7 shows an estimate of the static angular transmission error for the gear pair under consideration under no load condition. This is obtained numerically and is imported into the computational model as a Fourier series with respect to the pinion angle. As anticipated, the meshing frequency is dominant. This type of excitation is responsible for tonal noise generation, leading to a phenomenon known as the axle whine, particularly in differential systems [12, 14-15 and 51]. The dynamic response of the system is then exacerbated with subsequent generation of structure-borne and air-borne noises. Besides this source of excitation, a variation of the input torque with the pinion rotational frequency is considered. This is of similar nature to that introduced by internal combustion engine's crankshaft torsional oscillations, known as engine order vibration [52]:

$$
T_{p}=T_{p 0}\left(1+0.1 \cos \left(\frac{\omega_{m e s h}}{N} t\right)\right)
$$

The static component $T_{p 0}$ of the input torque has been selected so that under steady state conditions, the idealised kinematic condition based on the instantaneous transmission ratio is achieved as:

$$
T_{p 0}=\frac{R_{p}}{R_{g}} T_{g 0}
$$

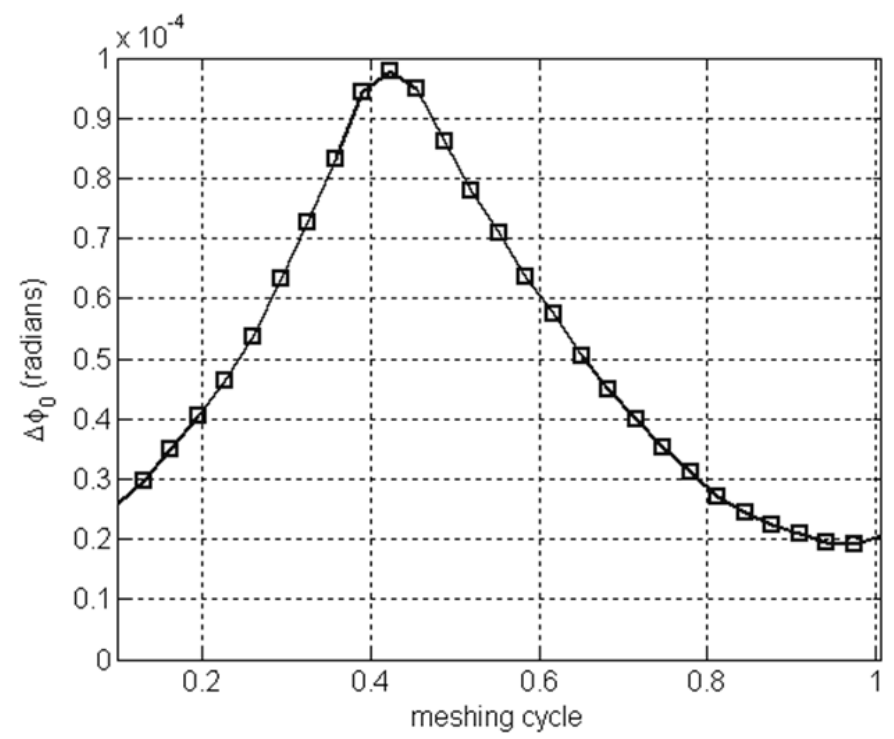

Figure 7: Static transmission error during a complete meshing cycle

The first objective of the current investigation is to compare the proposed initial formulation for dry contact with previously reported models which have relied on reducing the system model to a single DOF [14]. Integration of the equations of motion is achieved, using the 'ODE45' solver in MATLAB, which is based on the Runge-Kutta numerical integration algorithm. The total integration time is kept at a 
sufficient level in order to ensure that transient phenomena have fully decayed. The following set of data was used:

$c=2.2781 \cdot 10^{3} \mathrm{Ns} / \mathrm{m}, \quad T_{p 0}=50 \mathrm{Nm}, \quad I_{p}=1734 \cdot 10^{-6} \mathrm{kgm}^{2} \quad$ and $\quad I_{g}=5.81 \cdot 10^{-2} \mathrm{kgm}^{2}$

The meshing damping coefficient $c$ is chosen to correspond to a damping ratio of 0.03 (in accordance with typical values stated in reference [15]).

Figure 8a shows the dynamic transmission error variation with respect to the meshing frequency for both the single and two DOF models. The latter exhibits periodic solutions of higher amplitudes for a wide frequency region compared to the single DOF system. As a result, the two DOF system shows teeth separation at much lower frequencies (Figure 8b).
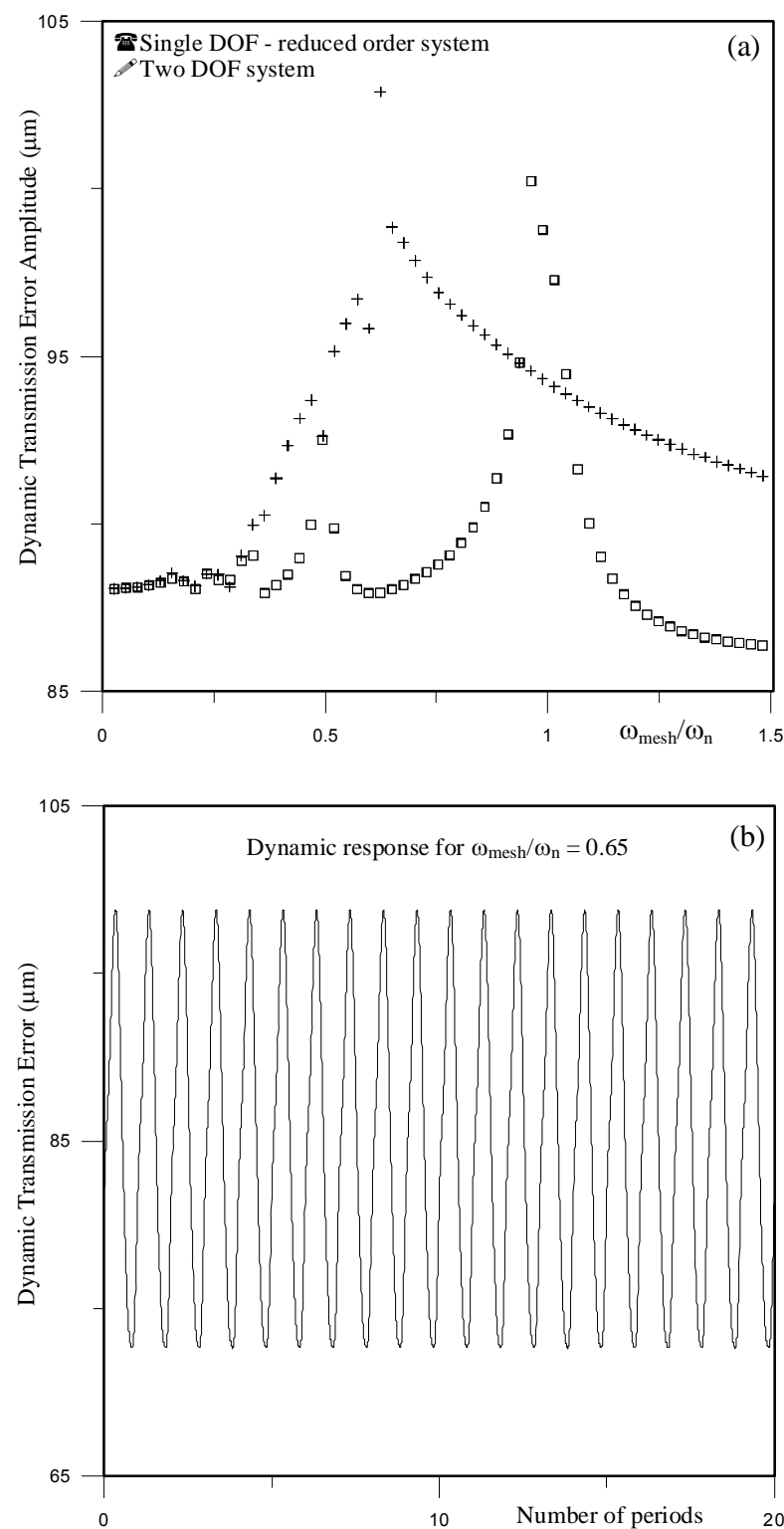

Figure 8: (a) Comparison of the dynamic transmission error amplitude variation for single and two DOF systems and dynamic response of the two DOF system at

(b) $\omega_{m e s h}=0.65 \omega_{n}$ 
The comparison of dynamic transmission error as acquired by both approaches is depicted in Figure 9 (where $T_{n}=\frac{2 \pi}{\omega_{n}}$ ), and the corresponding FFT spectra are shown in Figure 10. In this case the ratio of the meshing to natural frequency is found to be 0.3. From both the dynamic response histories and their spectra, it can be seen that the oscillating component of dynamic transmission error assumes higher values and shows more complex variations when the two DOF model is used. Additionally, there is the possibility of a super-harmonic resonance lying within this meshing frequency region, since the excitation frequency is close to one third of natural frequency. The above occurs as the result of the inclusion of rate of radii change in the equations of motion. Therefore, the energy contributions in the FFT spectra are also visible after the third meshing order of the two DOF model, whereas in the case of the single DOF model, this is absent. This explains the sharper peaks evident in the dynamic response when the two DOF model is considered. It seems that these peaks correspond to the contribution of the natural frequency with the possibility for the presence of a super-harmonic response.

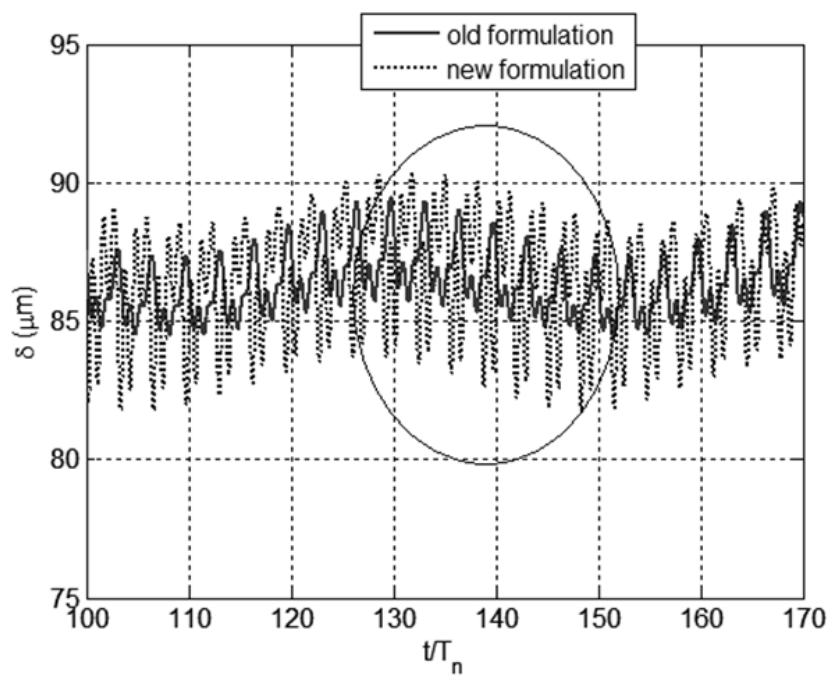

(a)

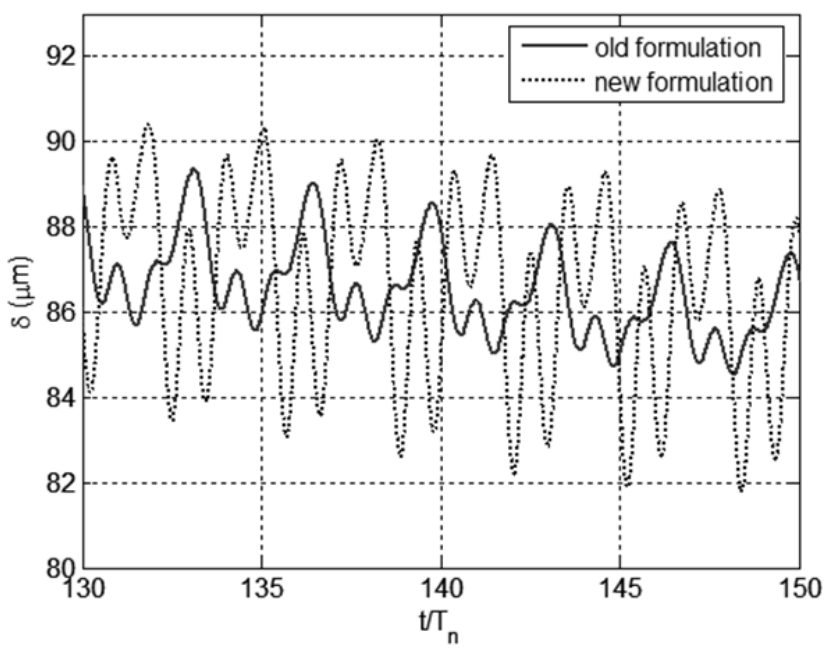

(b)

Figure 9: Time histories of the dynamic transmission error when $\omega_{\text {mesh }}=0.3 \omega_{n}$;

(a) general view (b) enhanced view

- single DOF - reduced order system (old formulation) double DOF (current formulation) 


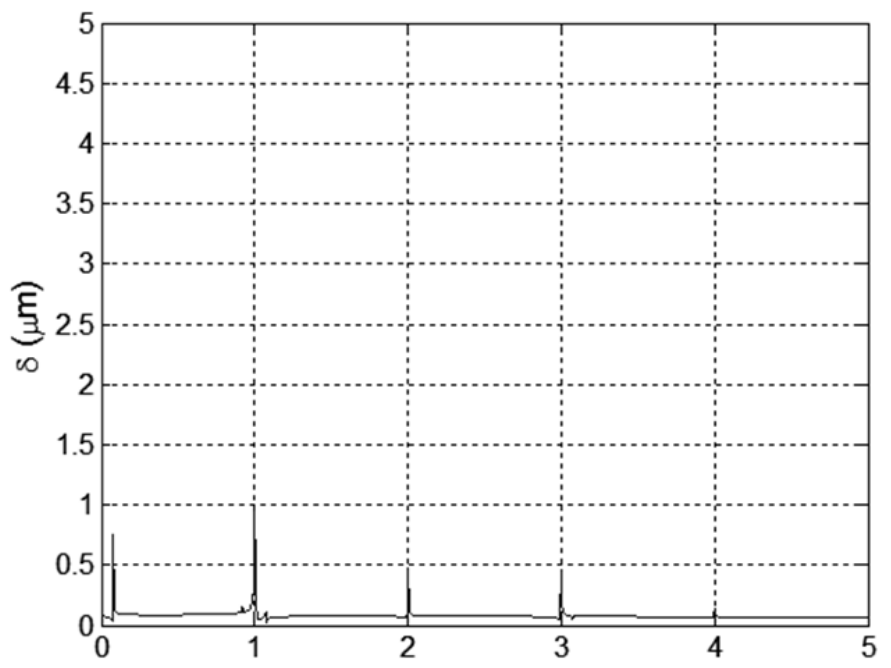

(a)

mesh order

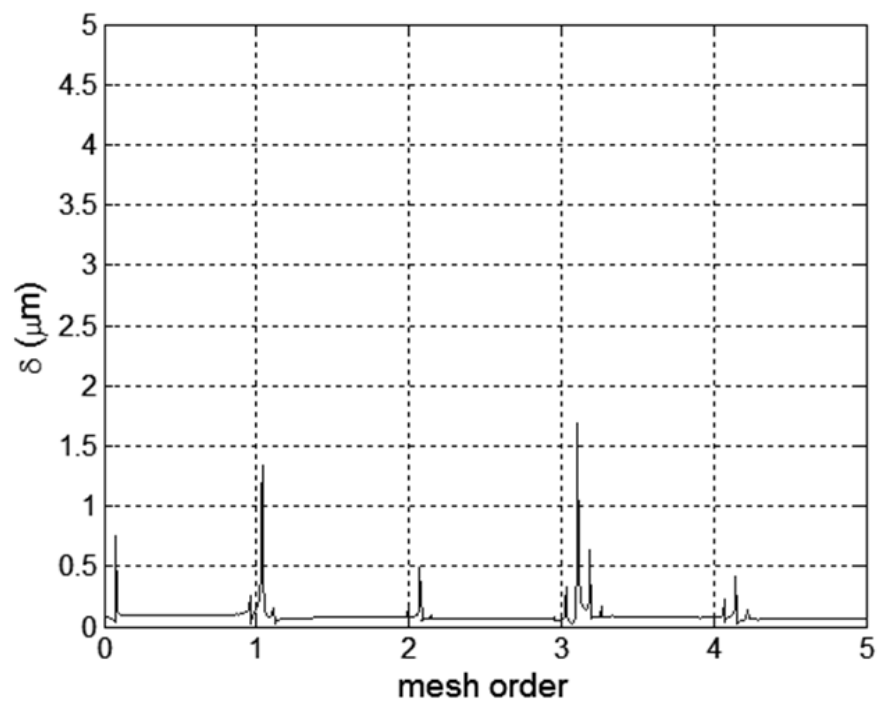

Figure 10: FFT spectra of the dynamic transmission error when $\omega_{\text {mesh }}=0.3 \omega_{n}$; (a) single DOF (b) two DOF system 


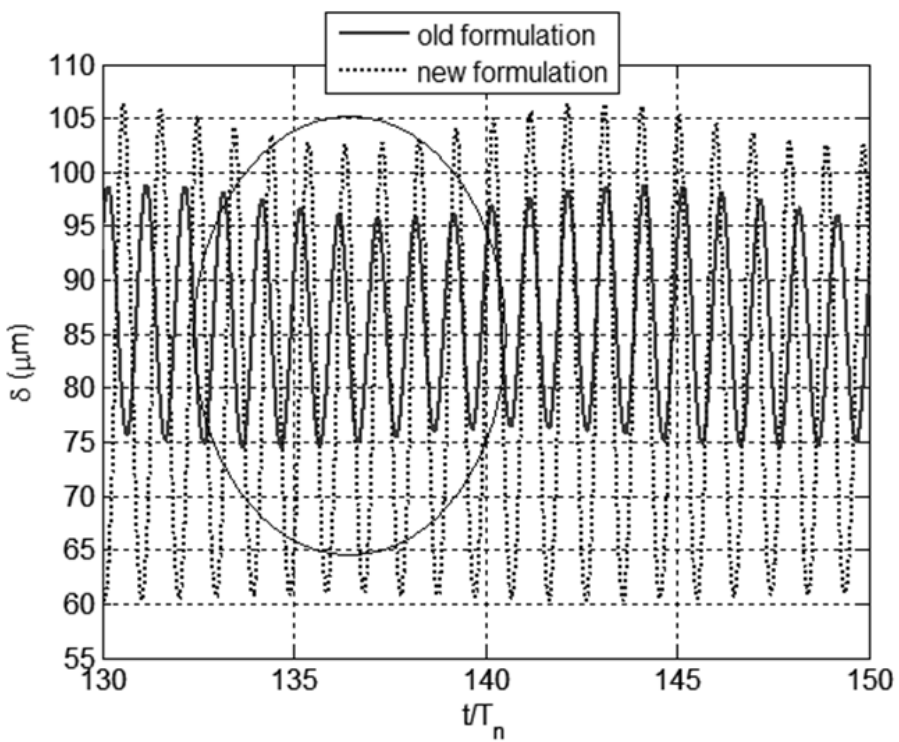

(a)

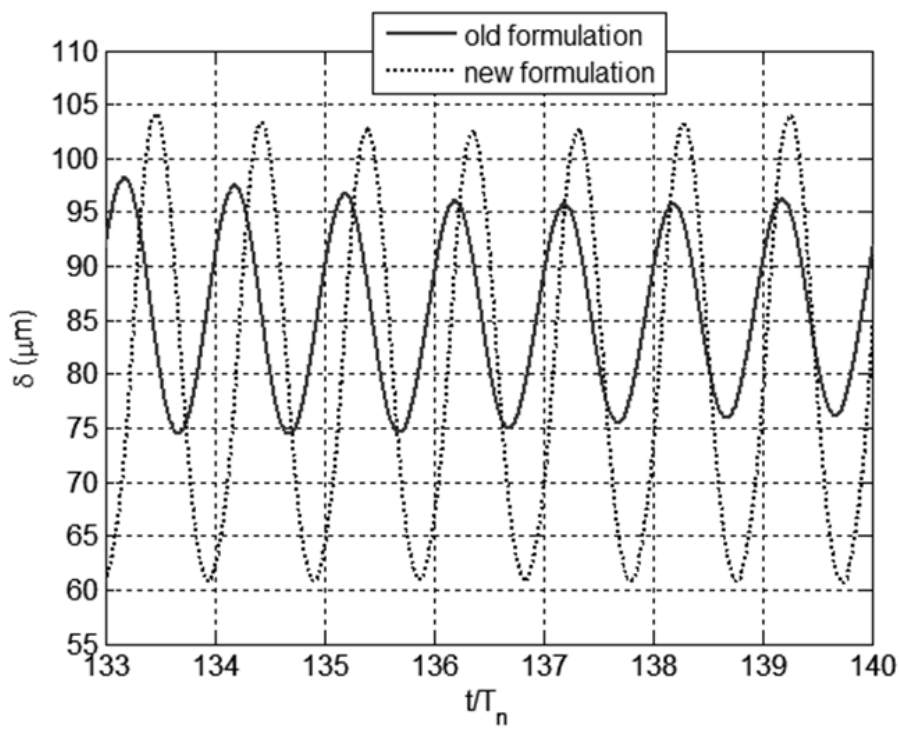

Figure 11: Time histories of the dynamic transmission error when $\omega_{\text {mesh }}=\omega_{n}$;

(a) general view (b) zoomed-in view

— single DOF - reduced order system (old formulation), double DOF (current formulation)

The same effect can be observed in the frequency region in the vicinity of the primary resonance, namely when the meshing frequency coincides with the natural response (Figures 11 and 12). In this case, the two DOF system reveals a more dramatic loss of contact and tooth separation compared with the single DOF model, since the absolute relative displacement drops below the backlash limits $( \pm 75 \mu \mathrm{m})$. The contribution of the resonance in the corresponding FFT spectra is again underestimated by the single DOF model, where the oscillating term of the dynamic transmission error is almost $50 \%$ lower than that predicted by the two DOF model. This is verified by the contribution of the first meshing order in the FFT spectra of Figure 12. As seen from Figure 11, the single DOF analysis hardly captures any loss of contact at the primary resonance. On the other hand, the two DOF model predicts a distinct loss of contact, showing that the non-linear effects are strongly related to the rate of change of contact radii, corresponding to the varying mesh vector. 
However, in order to draw more comprehensive conclusions, a thorough comparison of the dynamics of the two systems should be made for a broader frequency range while considering several levels of magnitude of external excitation.

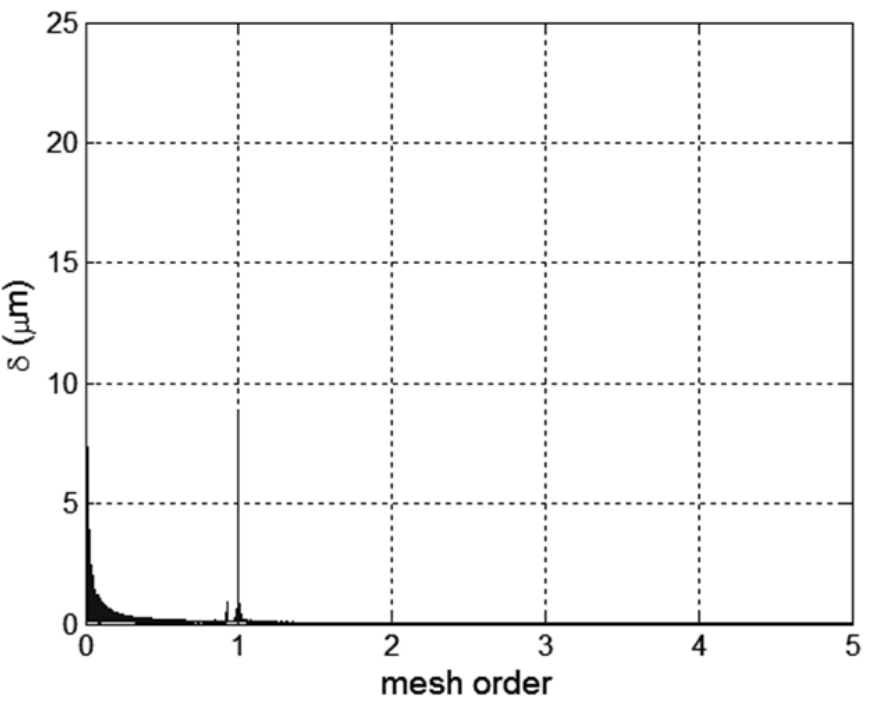

(a)

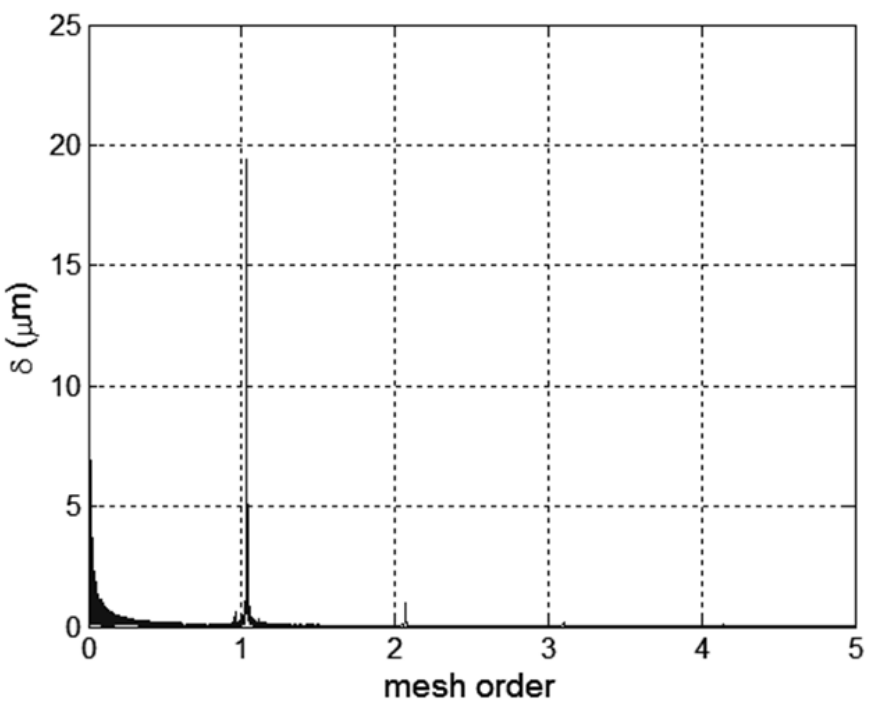

(b)

Figure 12: FFT spectra of the dynamic transmission error when $\omega_{\text {mesh }}=\omega_{n}$;

(a) single DOF (b) two DOF system

At this point it was deemed necessary to compare the response of the two DOF system with constant contact radii (equal to their mean values) versus that of the single DOF model. Figure 13 shows the comparison of the predicted responses, whereas Figure 14 depicts the corresponding FFT spectra. It can be clearly seen that when the contact radii are kept constant the system response is very close to that predicted by the single DOF system. Therefore, a single DOF system provides sufficient accuracy for cases with constant contact radii, this being a characteristic of spur gear pairs. The formulation proposed in this paper reveals aggravated dynamic response near resonant conditions by considering the spatial variation of the contact radii. Previous modelling approaches seem to have overlooked the importance of the contact radii variation, however small its magnitude may be (Figures $6 b, 6 c$ ). It has 
been previously suggested [15] that only a variation above $2 \%$ in the contact radii would play a significant role in the dynamics of a hypoid gear set. However, even with a smaller variation this effect can be significant, particularly at higher rotational speeds (meshing frequencies) - as it has been shown in the current analysis.

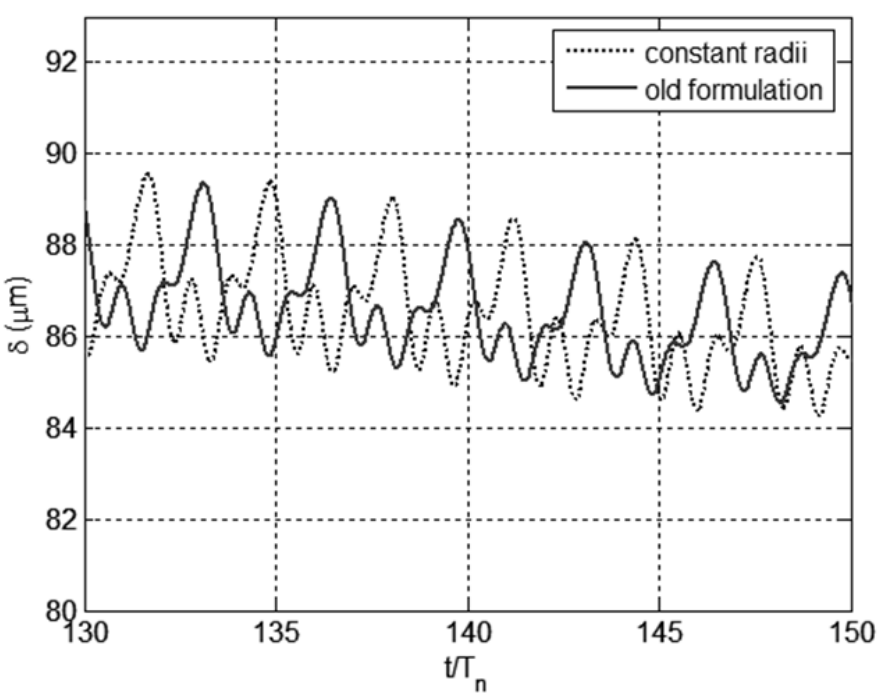

(a)

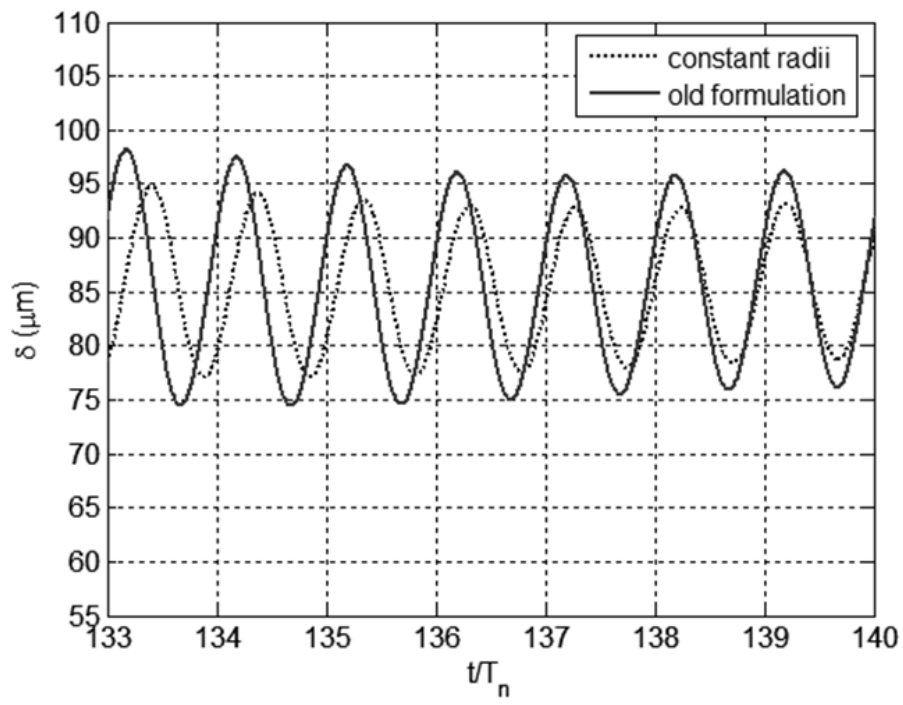

(b)

Figure 13: Time histories of the dynamic transmission error for constant contact radii when

(a) $\omega_{\text {mesh }}=0.3 \omega_{n}$, (b) $\omega_{\text {mesh }}=\omega_{n}$

- single DOF - reduced order system (old formulation), constant radii

The following section of this study describes the effect of friction in the gear pair dynamics. The lubricant, whose properties are listed in Table 2, is a typical differential oil used in light trucks and SUVs. 


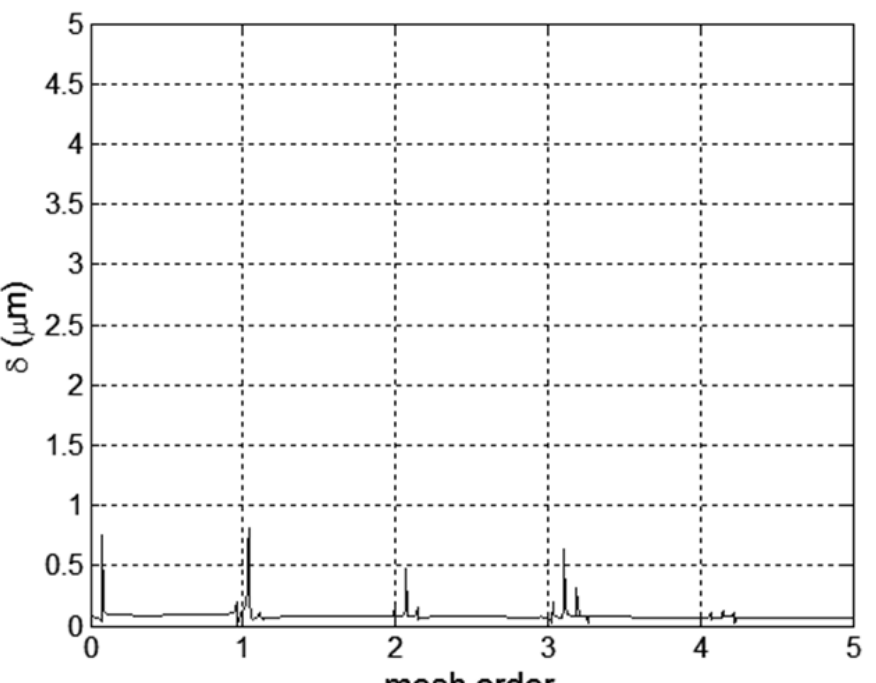

(a)

mesh order

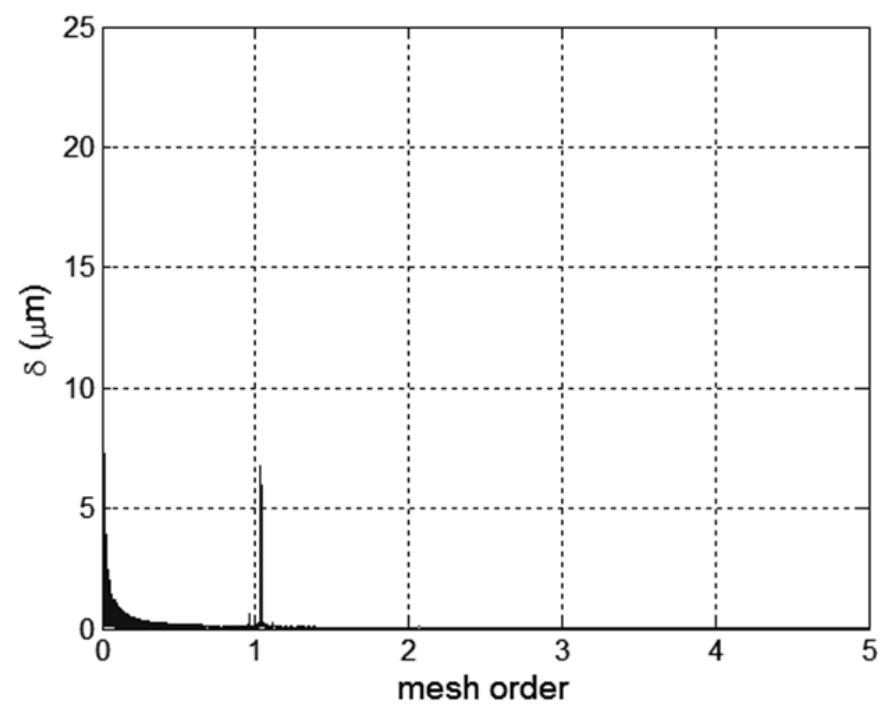

Figure 14: FFT spectra of the dynamic transmission error for constant contact radii when (a) $\omega_{\text {mesh }}=0.3 \omega_{n}$, (b) $\omega_{\text {mesh }}=\omega_{n}$

Table 2: Lubricant properties

\begin{tabular}{|l|l|}
\hline Kinematic viscosity at $100^{0} C(\mathrm{cSt})$ & 16.7 \\
\hline Kinematic viscosity at $40^{\circ} \mathrm{C}(\mathrm{cSt})$ & 109.1 \\
\hline Dynamic viscosity at $100^{0} \mathrm{C}(\mathrm{Pa} \cdot \mathrm{s})$ & 0.0145 \\
\hline Dynamic viscosity at $40^{0} \mathrm{C}(\mathrm{Pa} \cdot \mathrm{s})$ & 0.09483 \\
\hline Density $\left(\mathrm{kg} / \mathrm{m}^{3}\right)$ & 870 \\
\hline Thermal conductivity at $100^{0} \mathrm{C}(\mathrm{W} / \mathrm{mK})$ & 0.1077 \\
\hline Thermal conductivity at $40^{0} \mathrm{C}(\mathrm{W} / \mathrm{mK})$ & 0.1121 \\
\hline Pressure viscosity coefficient $\left(\mathrm{Pa}^{-1}\right)$ & $14.4^{*} 10^{-9}$ \\
\hline
\end{tabular}




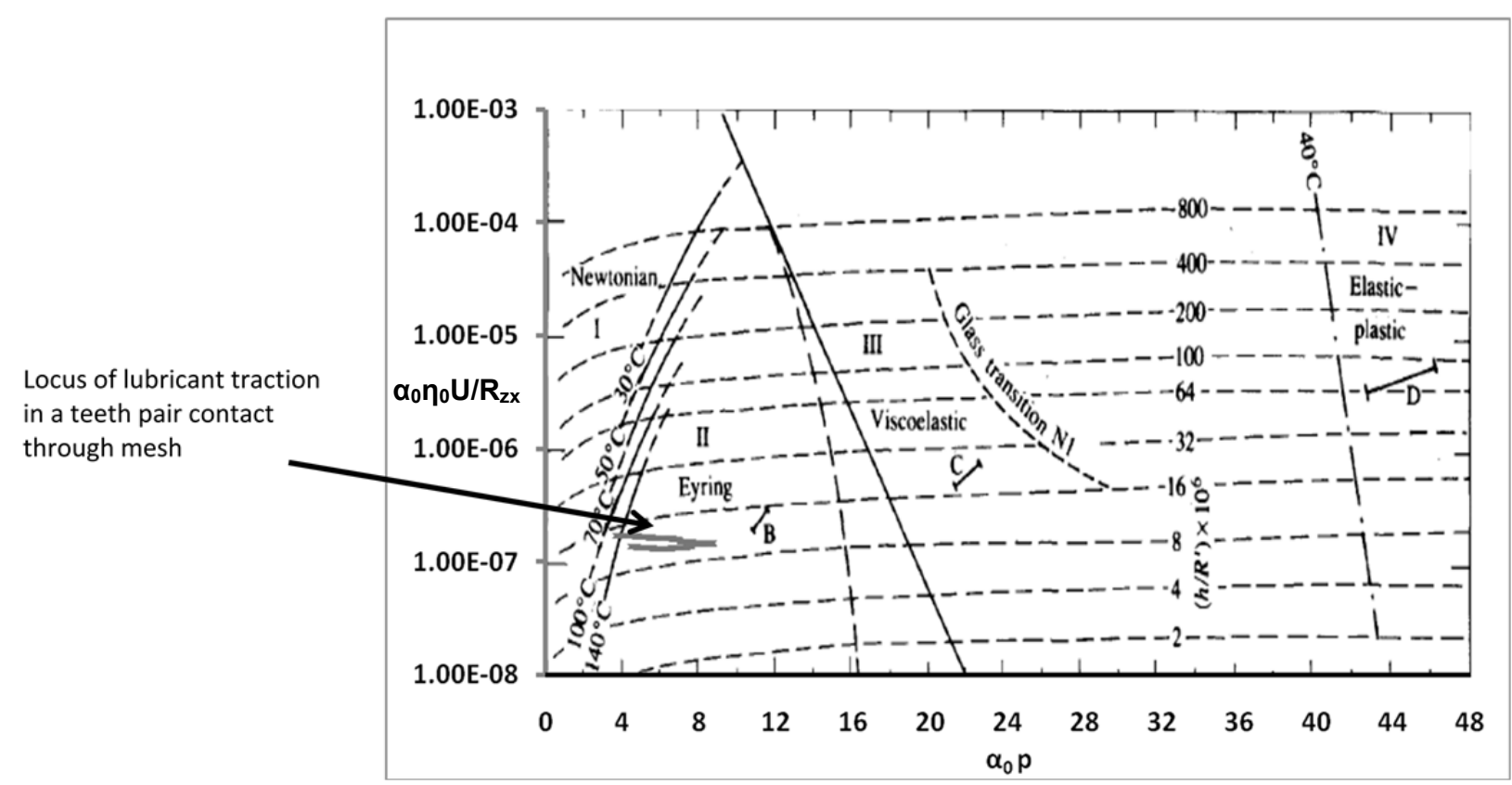

Figure 15: Representation of a meshing cycle inside a traction map for a high viscosity mineral oil $\left(\omega_{\text {mesh }}=0.3 \omega_{n}\right)$ (after Evans and Johnson [53])

Since all the necessary parameters with respect to the angular positions of the gears are known for every time step of simulation, the lubricant film thickness can be calculated. This is accomplished by setting up an iterative process, when applying the Grubin's analytic solution - given by equation (10) - combined with the thermal analysis, highlighted in section 2.3.4. After the in situ lubricant properties are derived, viscous and boundary friction contributions are calculated. The total frictional torque is incorporated in the equations of motion as an additional external excitation term (as depicted in the computational flowchart). It is important to note that the Eyring formulation is consistent with two facts observed during the numerical simulations: (a) the shear stress derived by a thermal Newtonian model exceeds the limiting Eyring shear stress and (b) the regime of traction falls within the Eyring region [53] (Figure 15). The prevailing region of lubricant traction for the current analysis is indicated on the traction map.

In Figures 16 and 17, the dynamic response of the system is depicted, when the mating surfaces are subjected to a mixed thermo-elastohydrodynamic regime of lubrication. The inlet temperature of the lubricant is $40^{\circ} \mathrm{C}$ and the RMS composite roughness is $0.5 \mu \mathrm{m}$. It can be seen that the two response curves of Figure 16 are almost identical (dry versus lubricated conditions).

The magnitude of teeth friction is not significant enough to result in high levels of torque variation. Furthermore, friction acts in a direction coincident with the relative sliding of the gear flanks. This direction is always normal to the line of action, where the torsional motion takes place. As a result, its effect on torsional dynamics is negligible [54]. Nevertheless, if additional lateral degrees of freedom were considered in the system and/or higher resisting loads were applied, then the influence of friction on the forces transmitted to the bearings could become significant [51]. 


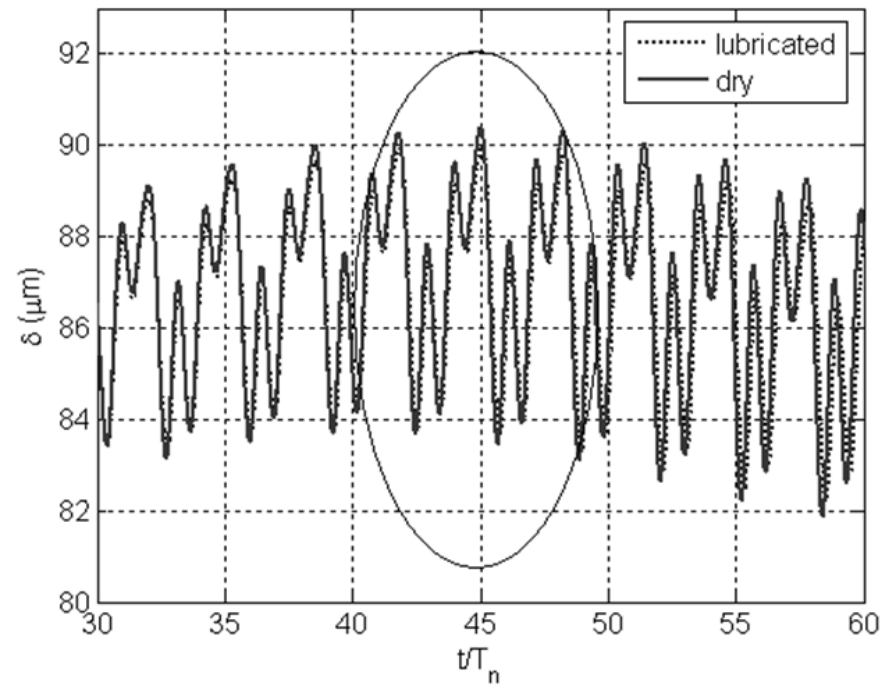

(a)

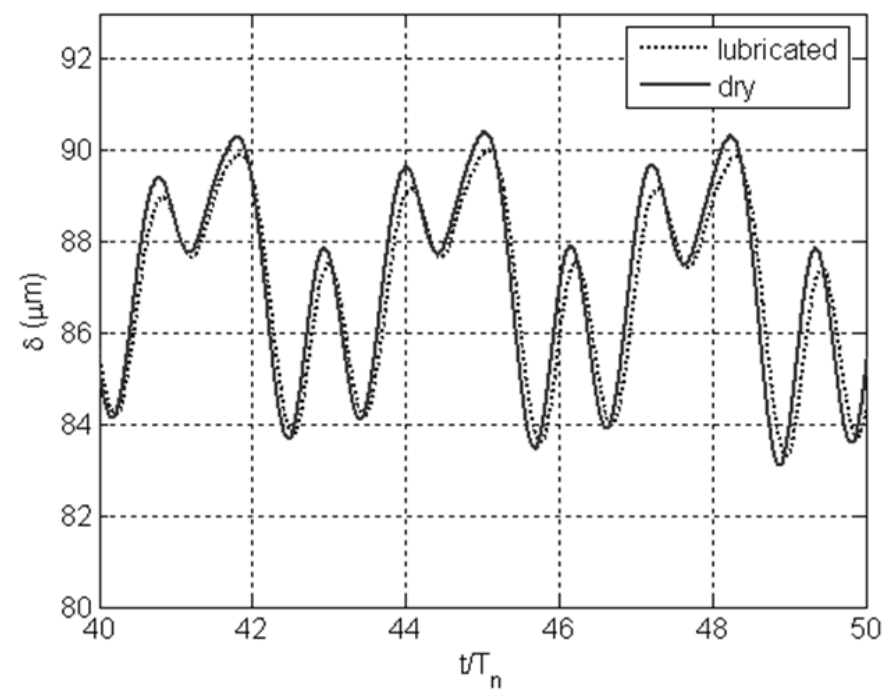

Figure 16: Time histories of the dynamic transmission for $\omega_{m e s h}=0.3 \omega_{n}$ :

(a) general view, (b) zoomed-in view

Dry conditions, Lubricated conditions

A dimensionless representation of the meshing cycle contact properties for the lubricated case is illustrated in Figure 18. The meshing frequency is $30 \%$ of the natural frequency. In these plots: $e_{0}=9.6 \cdot 10^{-7} \mathrm{~m}$ is the mean value of the static transmission error and $\omega_{p 0}=\frac{0.3 \omega_{n}}{N} \mathrm{rad} / \mathrm{sec}$ is the pinion angular velocity, when $\omega_{\text {mesh }}=0.3 \omega_{n}$. Figure 18 (a) shows the geometric and kinematic parameters influencing the lubricant film thickness, namely the equivalent radius of curvature and the entraining velocity of the lubricant along the direction of sliding. Both quantities increase during mesh prior to dropping at the end of the cycle, as expected. The temperature rise inside the contact occurs mainly due to the viscous shear of the lubricant, with its maximum value rising $3 \%$ above the inlet lubricant temperature (Figure 18b). The lubricant viscosity undergoes a significant increase by almost two 
orders of magnitude with respect to the inlet pressures due to the high contact pressures in the EHL regime (Figure 18b).

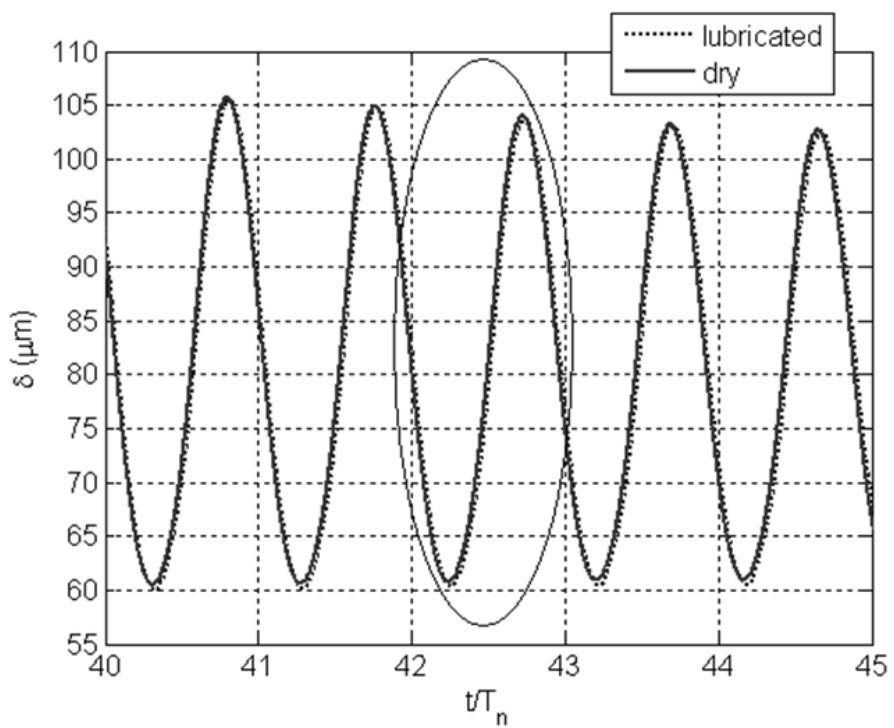

(a)

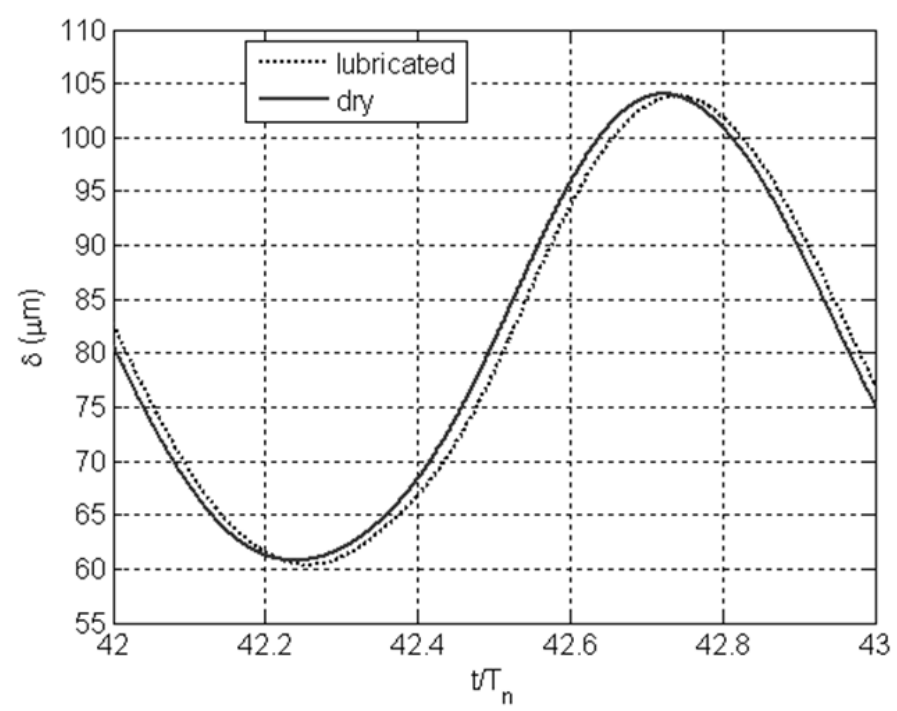

Figure 17: Time histories of the dynamic transmission for $\omega_{m e s h}=\omega_{n}$ :

(a) general view, (b) zoomed-in view

\section{- Dry conditions,}

Lubricated conditions

The contact load gradually increases inside the cycle, reaching a maximum value at the midpoint before decreasing until contact of the current teeth pair terminates (Figure 18c). The film thickness is almost constant throughout the mesh (Figure 18c). From equation (10) it can be seen that film thickness is mostly influenced by the effective curvature radius, entraining velocity and effective viscosity. It seems that any increase in film thickness on the account of the first two parameters is offset by the viscosity drop due to the contact temperature rise (Figure 18c). Therefore, the film varies only slightly, between 0.4 and $0.5 \mu \mathrm{m}$. The contact area depends primarily on the contact load and, therefore, it follows a similar pattern (Figure 18d). The shear rate seen in the same figure increases continually as an effect of the sliding velocity; a slight decline is observed at the end of the cycle. 
(a)

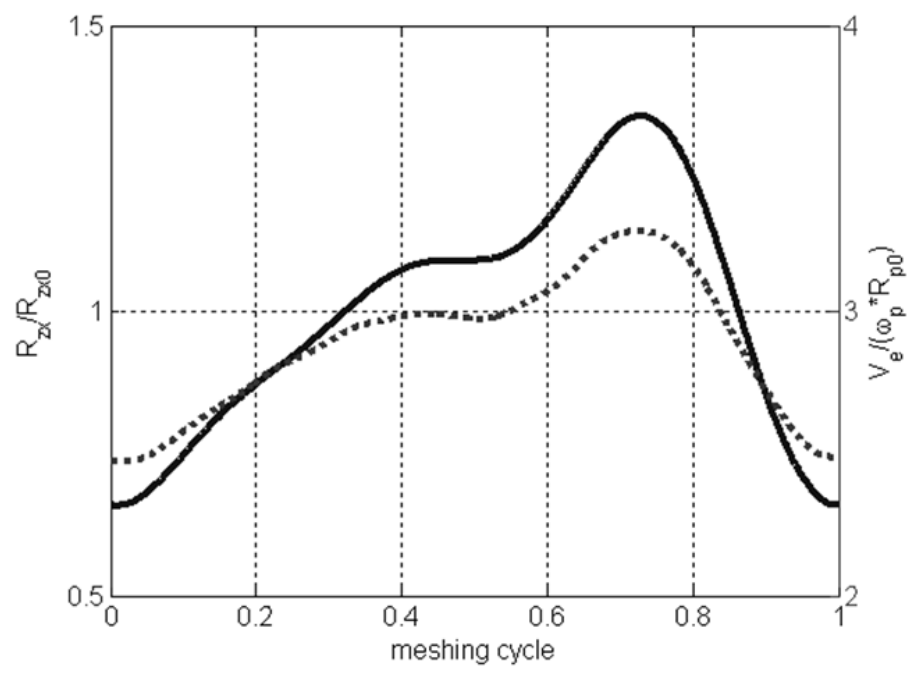

(b)
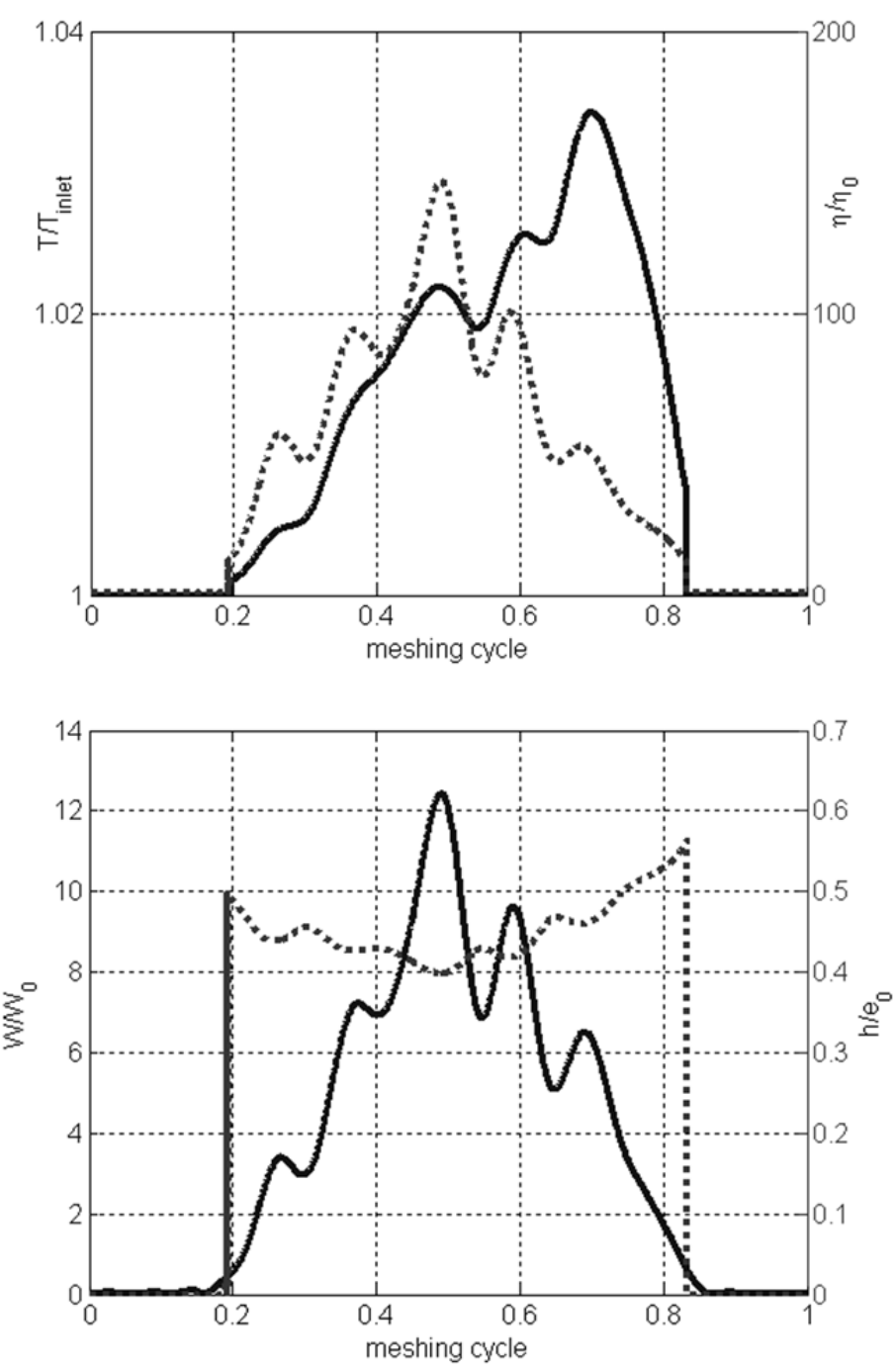

Figure 18 ....... (continued) 


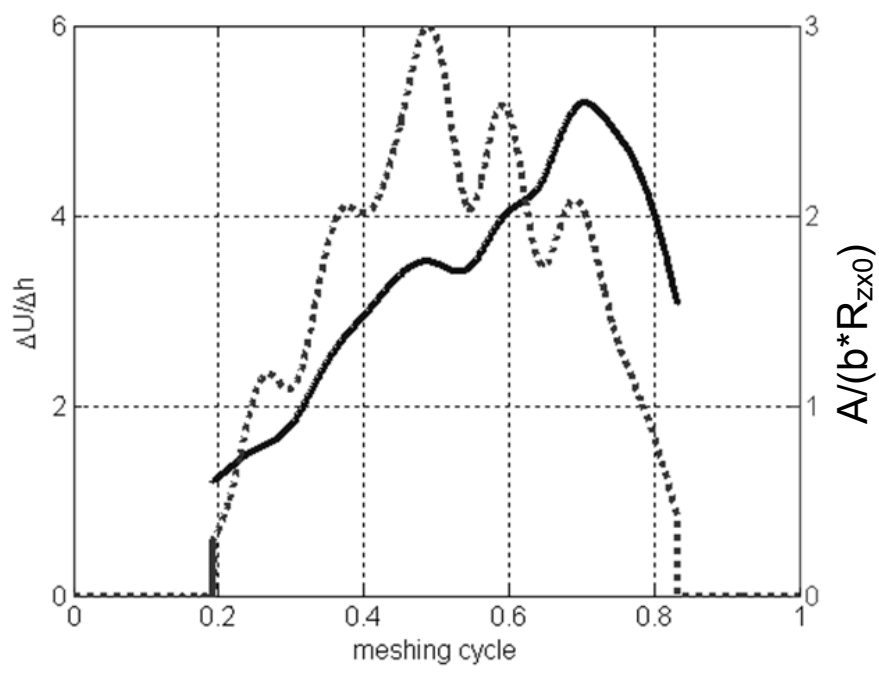

d)

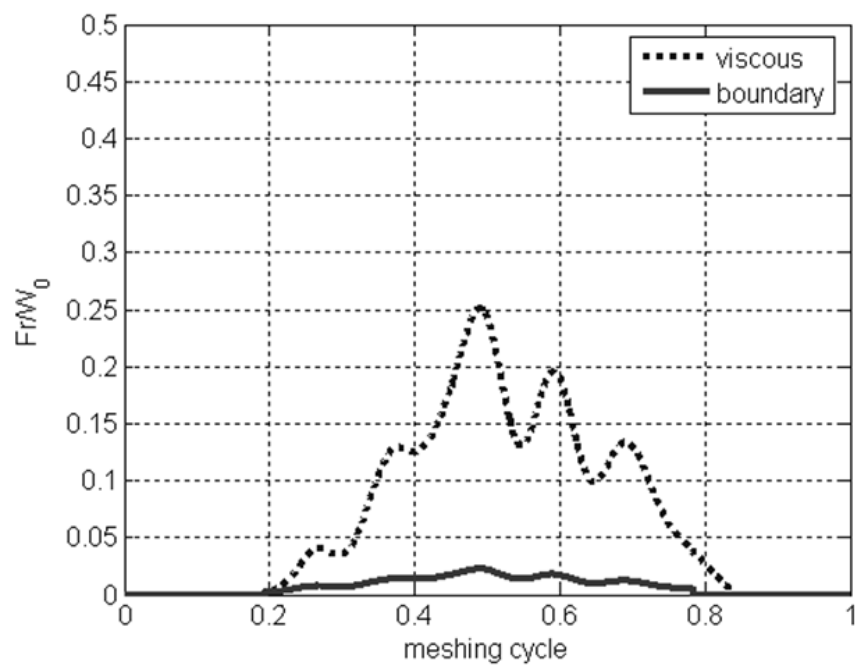

(e)

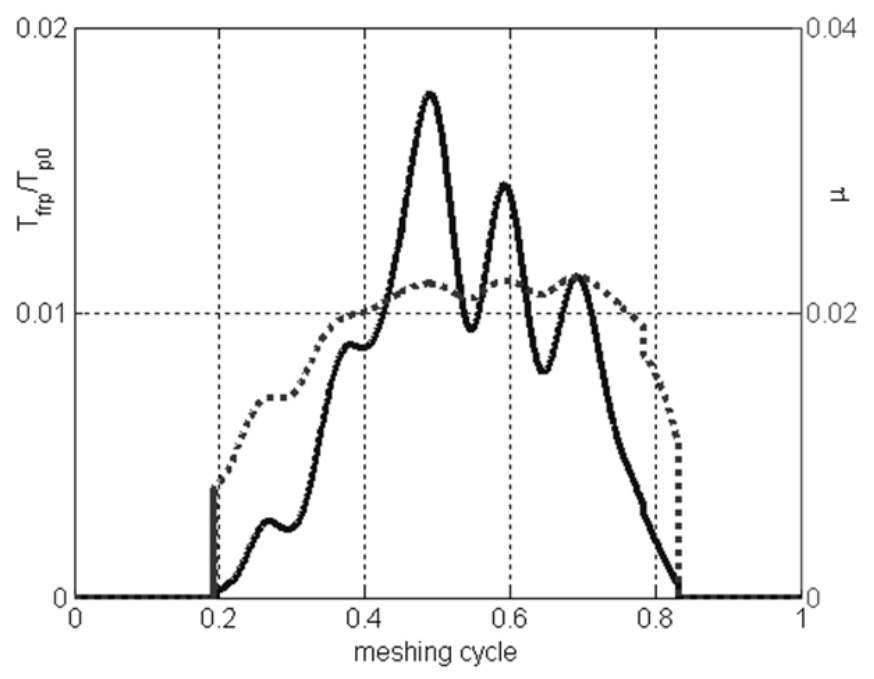

Figure 18: Teeth contact properties $\left(\omega_{\text {mesh }}=0.3 \omega_{n}\right.$, composite surface roughness $\sigma=0.5 \mu \mathrm{m}$, lubricant inlet temperature $40^{\circ} \mathrm{C}$ );
(a) $\hat{V}_{e},(\mathrm{~b})$ $\hat{\eta},(\mathrm{c})$ $\widehat{W}$, $\widehat{h}$,
(d)ــ $\frac{\Delta \hat{U}}{\Delta \hat{h}}$,
$\bar{A},(\mathrm{e})$
$\widehat{F}_{f r, b}$
$\hat{F}_{f r, v},(f)$
$\widehat{T}_{f r, p}$, $\mu$ 
The contribution of asperity interactions to the total friction force is minimal as depicted in Figure 18e; the latter is dominated by viscous shear. The coefficient of friction (Figure 18f) is typical of the EHL regime of lubrication. Nevertheless, the magnitude of frictional torque is trivial with respect to the external excitation. Hence, the torsional dynamics of the system remains almost unaffected.

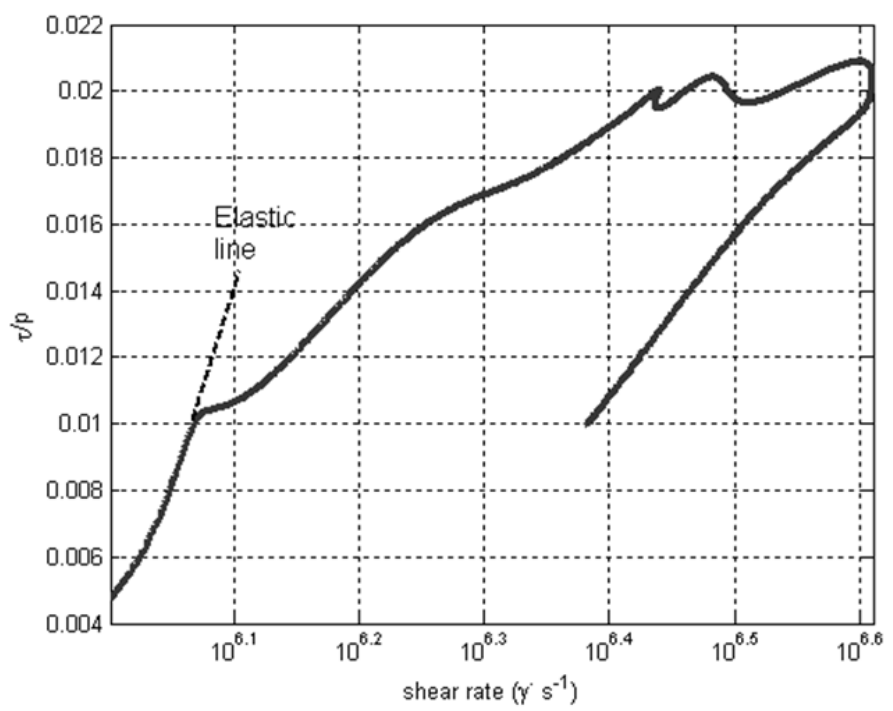

(a)

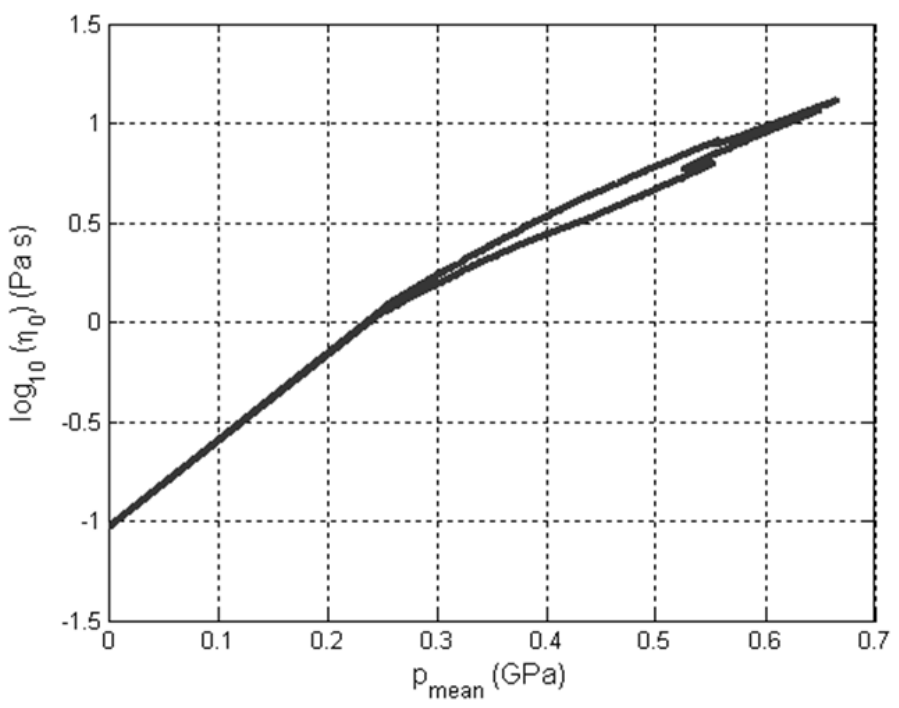

(b)

Figure 19: (a) Traction curve and (b) viscosity plot $\left(\omega_{\text {mesh }}=0.3 \omega_{n}\right.$, surface roughness $S_{\mathrm{rms}}=0.5 \mu \mathrm{m}$, lubricant inlet temperature $40^{\circ} \mathrm{C}$ )

The evidence for Eyring shear is visible in Figure 19a. The deviation from the linearity of Newtonian behaviour at $\tau / \bar{p} \approx 0.01$ is clear. The curve bends, and the magnitude of shear stress falls off from one which would be predicted by idealized Newtonian shear. The shape of the curve is qualitatively comparable to the experimental results derived by disc machine experiments [53]; the wiggling effect can be explained by the varying pressure and temperature values during meshing. The significant viscosity rise with respect to the mean pressure eventually leads to the attainment of a non-Newtonian Eyring regime of traction (Figure 19b, also see Figure 15). 
When the angular velocity of the pinion increases and approaches the natural frequency of the system, primary resonance occurs, which is marked by the onset of loss of contact. These contact conditions are shown in Figure 20. The loss of contact is clearly associated with zero contact load, which is present for almost one third of the meshing cycle (Figure 20c). Besides the impulsive nature of contact load due to tooth separation, the resonant conditions also induce a significant increase in the contact load at other times (compared with the results shown in Figure $18 \mathrm{c}$ for $\omega_{\text {mesh }}$ $\left.=0.3 \omega_{n}\right)$.

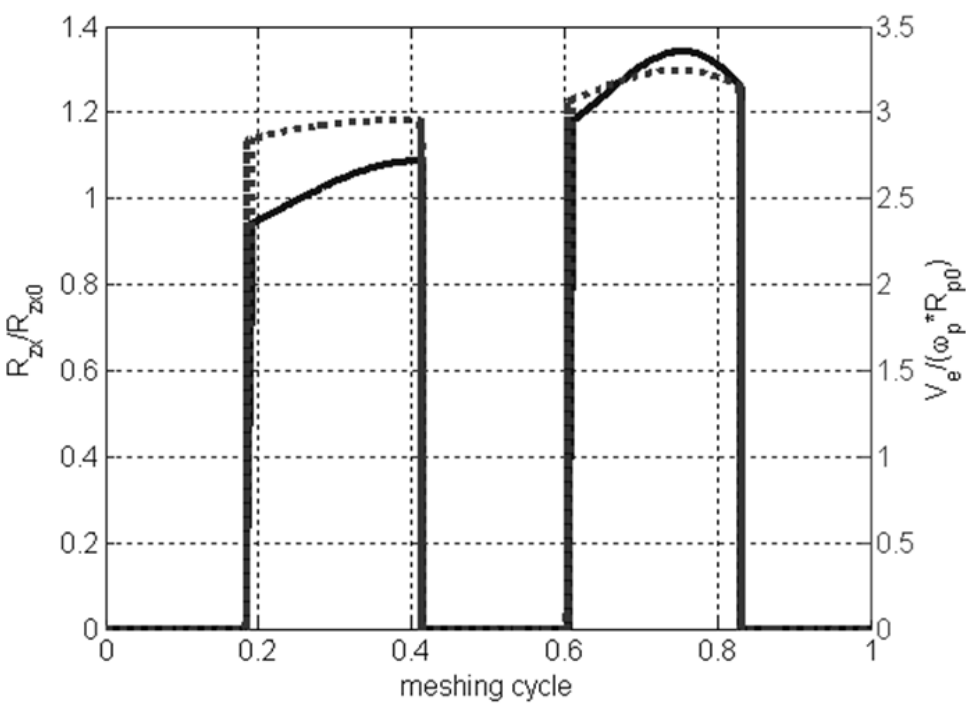

(a)

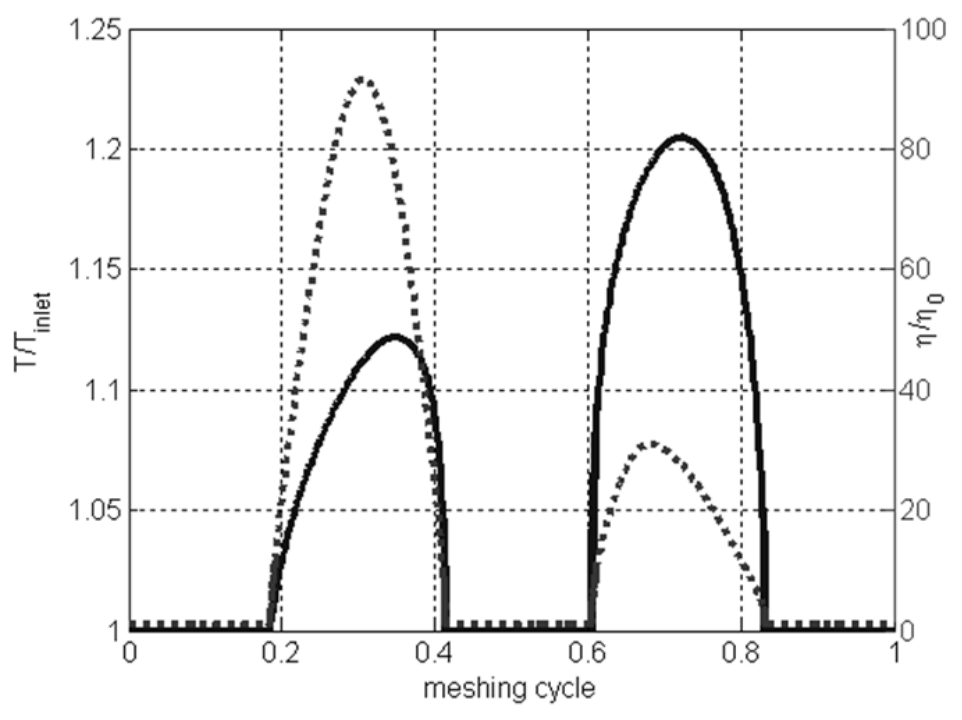

Figure $20 \ldots \ldots$ (continued) 


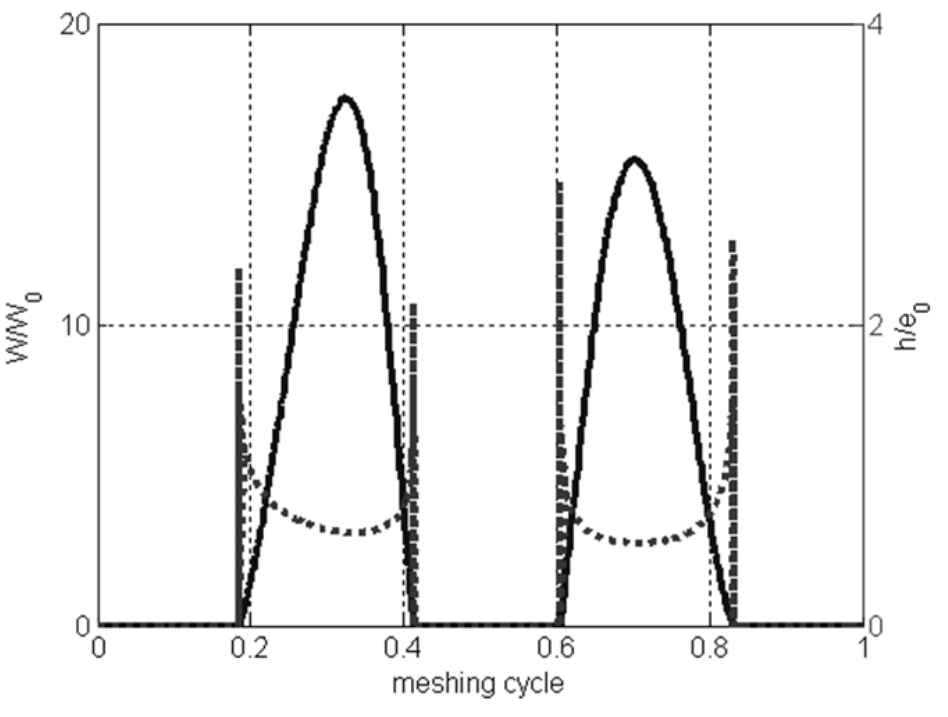

(c)

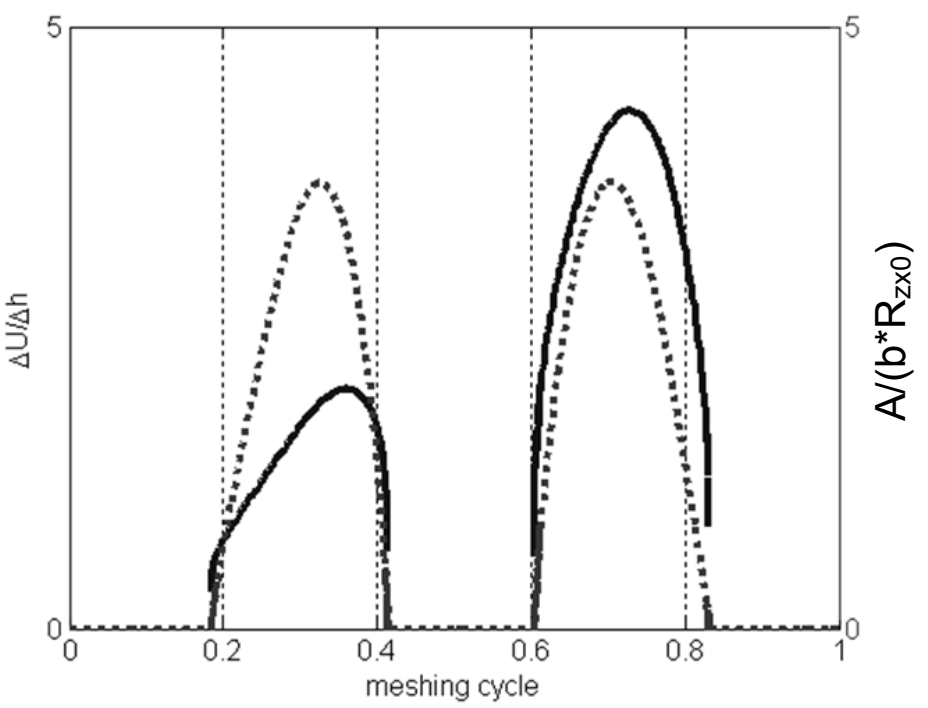

(d)

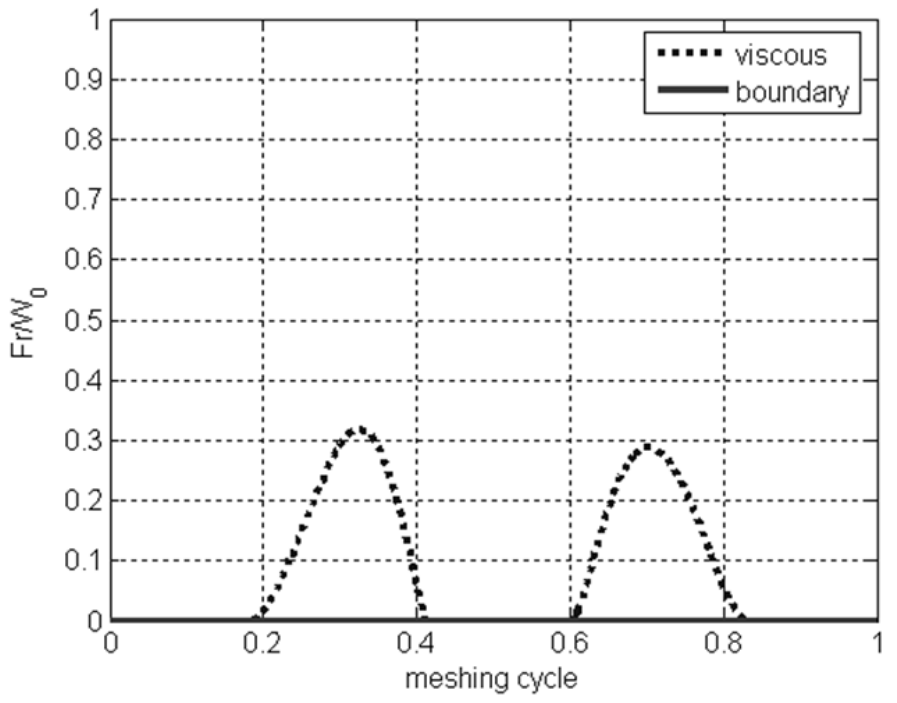

Figure $20 \ldots . .$. (continued) 


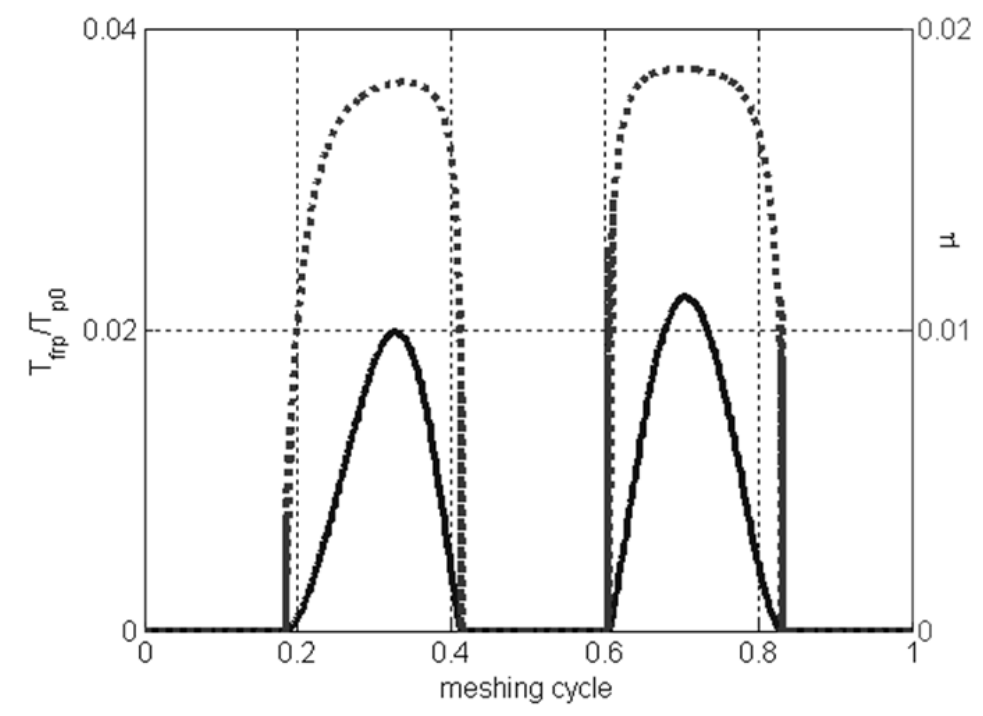

Figure 20: Teeth contact properties $\left(\omega_{\text {mesh }}=\omega_{n}\right.$, composite surface roughness $\sigma=0.5 \mu \mathrm{m}$, lubricant inlet temperature $40^{\circ} \mathrm{C}$ )

(a) $\widehat{V}_{e},(\mathrm{~b})-\hat{T}$, $\hat{\eta},(\mathrm{c})$ $\widehat{W}$, .

(d)- $\frac{\Delta \hat{U}}{\Delta \hat{h}}$,

$\bar{A},(\mathrm{e})$

$\widehat{F}_{f r, b}$, $\hat{F}_{f r, v},(\mathrm{f})$ $\widehat{T}_{f r, p}$ $\mu$

However, the film thickness remains independent of load owing to the thermal EHL conditions at high loads and rapid replenishment of a lubricant film subsequent to any momentary loss of contact (Figure 20c). Due to a higher angular velocity, the lubricant entraining velocity is increased (Figure 20a) and presents reduced fluctuations. This is as a result of the limited time that the teeth remain in contact. The entraining velocity has almost tripled compared with that in Figure 18a. Similar observations can be drawn for the radius of curvature, which also reaches higher values compared with that in Figure 18a. Consequently, aggravated viscous shear (as depicted in Figure 20b) results in a contact temperature rise of $20 \%$ in excess of the bulk lubricant temperature at the contact inlet meniscus. Thus, effective viscosity of the lubricant is reduced compared with that in Figure $18 \mathrm{~b}$ by almost a third. The combined effect of increased entraining motion and reduced viscosity yields the double peak in the time history of the lubricant film thickness. The peak value is almost $1 \mu \mathrm{m}$. The increase in the contact area (Figure 20d) as an effect of increased contact load combined with the shear effect results in higher levels of viscous friction (Figure 20e). Nevertheless, due to loss of contact, the frictional mechanism remains rather ineffective over a considerable part of the meshing cycle.

The influence of lubricant temperature at the contact inlet is depicted in Figure 21 for $\omega_{\text {mesh }}=0.3 \omega_{n}$. The inlet temperature is now set at $100^{\circ} \mathrm{C}$. The dimensionless temperature and viscosity graphs (Figure 21a) are derived for the parameters shown in Figure 18, so that an effective comparison can be made. In this case, the high contact velocity results in a significant drop in the lubricant viscosity, which is now almost a third of that in Figure 18. However, the temperature rises in the contact by around $20 \%$ (reaching a value of $145^{\circ} \mathrm{C}$ ), compared with a mere rise of $1-3 \%$ (corresponding to $41^{\circ} \mathrm{C}$ maximum temperature) in the case shown in Figure $18 \mathrm{~b}$. In turn, the film thickness (Figure 21b) is reduced to almost a fifth of that predicted in 
Figure $18 \mathrm{c}$ (the maximum value in Figure $21 \mathrm{~b}$ is just above $0.13 \mu \mathrm{m}$ ). This dramatic shear thinning of the lubricant film (also exhibiting shear rate values of more than two times those in Figure 18d) yields increased boundary friction. This contribution now exhibits comparable values to the viscous friction of the lubricant film (in Figure 21d, the boundary friction magnitude is about $20 \%$ of the maximum viscous friction values), when compared with that in Figure 18e. The simultaneous increase in shear rate and boundary friction together with a decline in effective viscosity yields a rise in frictional torque (Figure 21e). However, this only represents a rise of $0.5 \%$ compared with the results in Figure 18e.

(a)
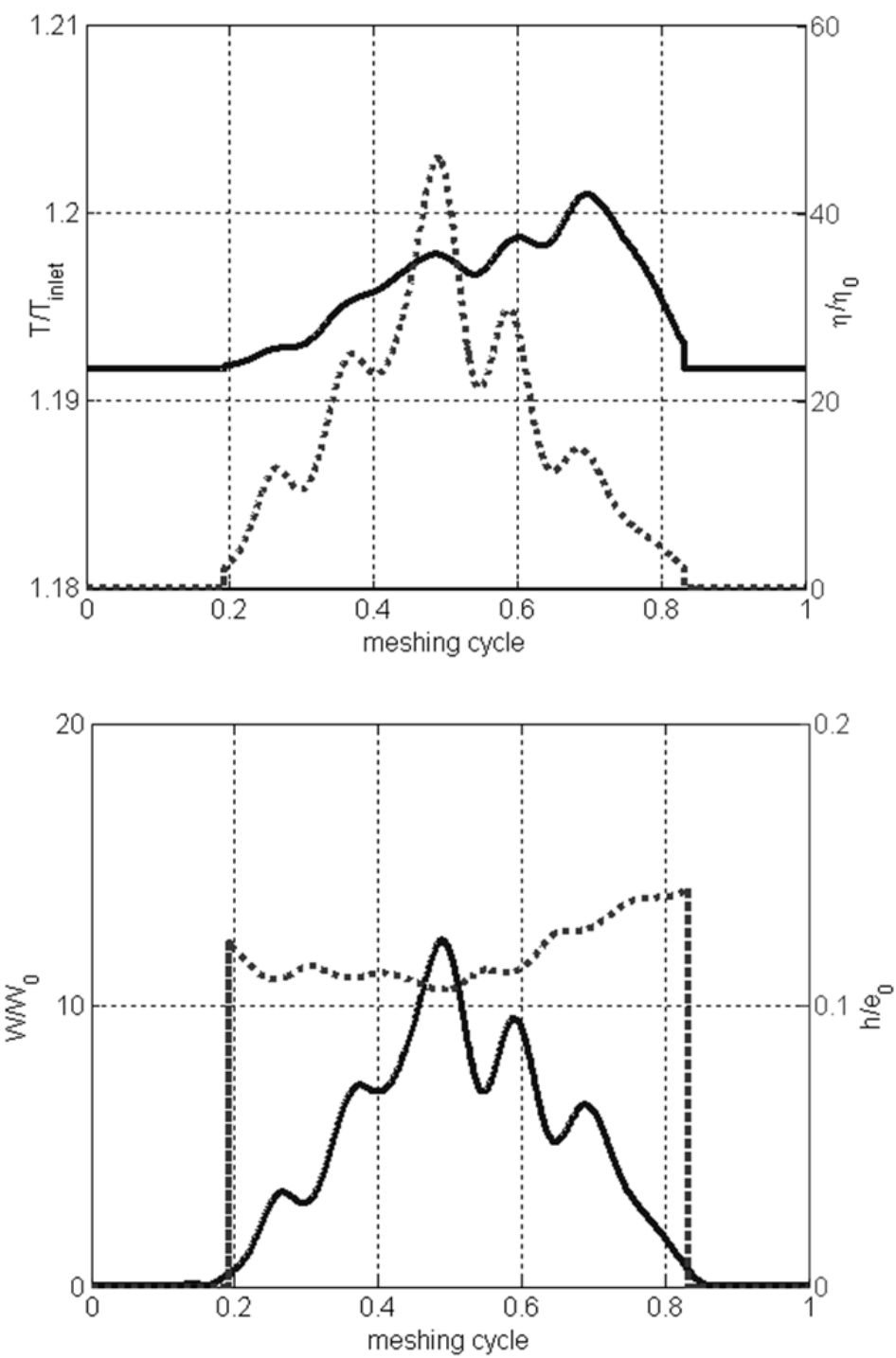

(b)

Figure $21 \ldots . .$. (continued) 
(c)
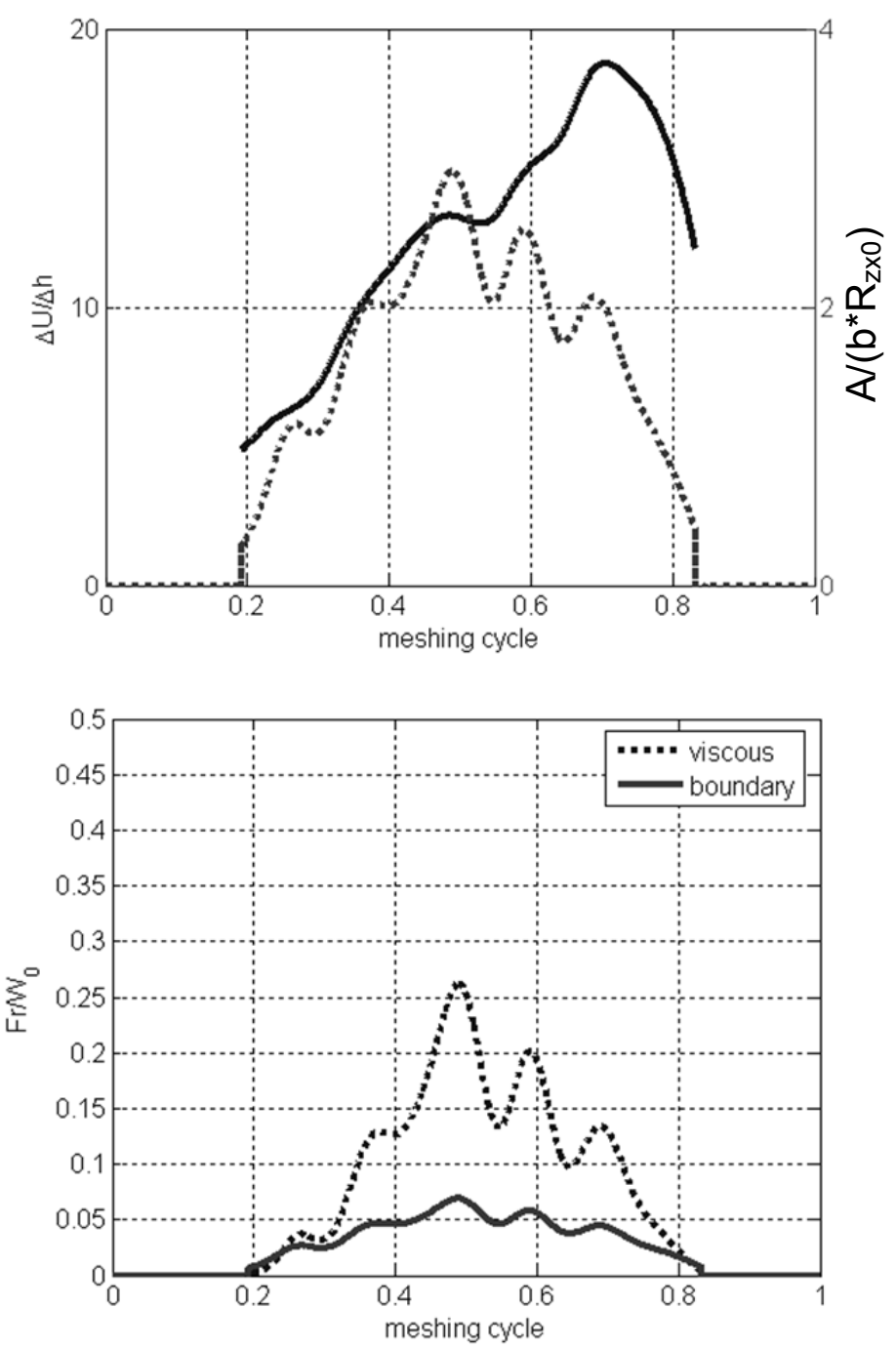

(d)

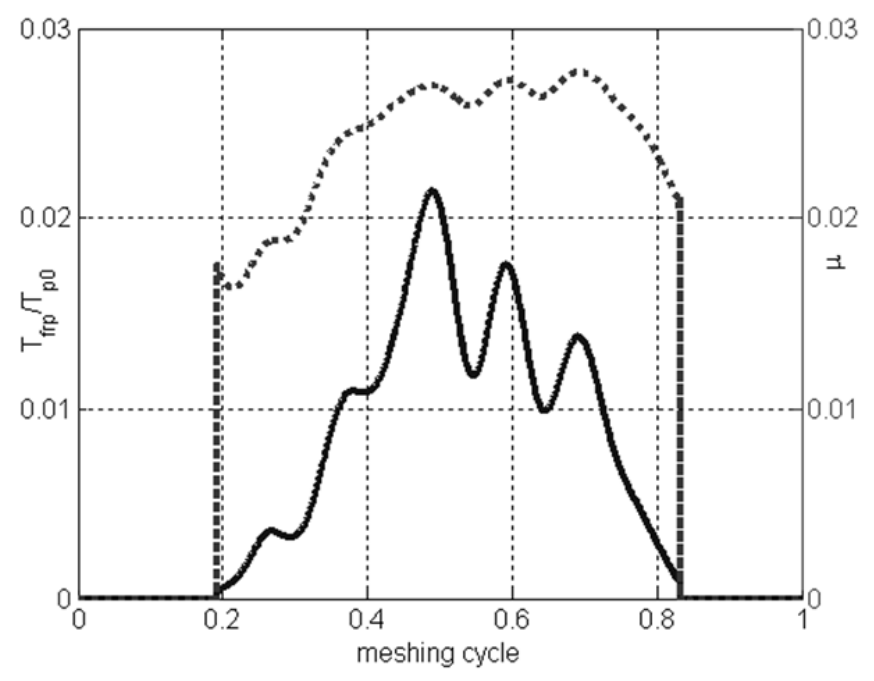

(e)

Figure 21: Contact properties $\left(\omega_{\text {mesh }}=0.3 \omega_{n}\right.$, composite surface roughness $\sigma=0.5 \mu \mathrm{m}$, lubricant inlet temperature $100^{\circ} \mathrm{C}$ )
(a) $\widehat{T}$,
$\hat{\eta},(\mathrm{b})$ $\widehat{W}$,
$\hat{h}$, (c) A ,
(d)
$\hat{F}_{f r, b}$
$\widehat{F}_{f r, v},(\mathrm{e})$
$\widehat{T}_{f r, p}$, $\mu$ 


\section{Conclusions}

A new method for analyzing dynamics of hypoid gear pairs is presented. The mathematical model relies essentially on two torsional degrees of freedom due to the rate of change of contact radii. The main difference from previously reported formulations is the introduction of the dynamic transmission error in an integral form, accounting for the variation in the contact radii. The current method predicts an aggravated dynamic response compared with the investigations previously reported in the literature, while yielding more severe non-linear effects near the primary resonance. These are characterised by severe loss of contact, which is typical of gear pair systems with high impacts, which sometimes lead to powertrain Noise, Vibration and Harshness phenomena (e.g. rattle, axle whine). Therefore, the presented method aims to contribute to more accurate investigations of the root causes of powertrain $\mathrm{NVH}$ issues.

The interaction of friction with the system dynamics is investigated by including an analytical thermal model to represent lubricated contact characteristics in a more realistic manner, where temperature plays an important role, not often acknowledged in reported analyses. Due to relatively high conjunctional pressures and sliding velocity, the regime of traction lies within the Eyring region. This indicates thin films with increasing asperity interactions and rising contact temperatures. However, friction torque appears to only marginally affect the torsional dynamics of the system. Nonetheless, the effect can be more significant if the lateral motions of the gear wheels were to be considered and/or in cases of high transmitted loads. This needs to be thoroughly investigated in a future parametric study.

\section{Acknowledgments}

The authors wish to express their gratitude to Dr. Sandeep Vijayakar of Advanced Numerical Solutions Inc. for supplying a license of the CALYX software and supporting the TCA part of this work. Thanks are also due to Ford Motor Company for collaboration in the axle whine project, particularly Prof. Patrick Kelly and Mr. Tim Saunders.

\section{Appendix}

\section{Nomenclature}

\begin{tabular}{|c|c|}
\hline $\begin{array}{l}\bar{A} \\
A\end{array}$ & $\begin{array}{l}\text { dimensionless quantity expressing the lubricant properties } \\
\text { apparent contact area (Hertzian) }\end{array}$ \\
\hline$A_{a}$ & asperity contact area \\
\hline$b$ & $\begin{array}{l}\text { half gear backlash } \\
\text { dampina coefficient in the direction of mesh }\end{array}$ \\
\hline $\begin{array}{l}d \\
e(t)\end{array}$ & $\begin{array}{l}\text { minor half-width of contact ellipse } \\
\text { static transmission error }\end{array}$ \\
\hline $\begin{array}{l}E \\
f(x)\end{array}$ & $\begin{array}{l}\text { modulus of elasticity } \\
\text { deflection function due to backlash }\end{array}$ \\
\hline
\end{tabular}




\begin{tabular}{|c|c|}
\hline$F_{f r}$ & total friction force \\
\hline$F_{b}$ & boundary friction \\
\hline$F_{v}$ & viscous friction \\
\hline$h_{0}$ & elastohydrodynamic film thickness \\
\hline$I_{p}, I_{g}$ & mass moments of inertia of pinion and gear \\
\hline$\vec{j}_{p}, \vec{j}_{g}$ & normal unit vectors \\
\hline$k_{m}$ & mesh stiffness \\
\hline $\begin{array}{l}K \\
l f\end{array}$ & $\begin{array}{l}\text { thermal conductivity of lubricant oil } \\
\text { load distribution factor }\end{array}$ \\
\hline $\begin{array}{l}m \\
m_{e q}\end{array}$ & $\begin{array}{l}\text { pressure coefficient of the boundary shear strength } \\
\text { equivalent mass of gear pair }\end{array}$ \\
\hline $\begin{array}{l}N \\
p\end{array}$ & $\begin{array}{l}\text { number of pinion teeth } \\
\text { contact pressure due to dynamic mesh force }\end{array}$ \\
\hline$p_{m}$ & mean Hertzian contact pressure \\
\hline$P_{a}$ & load carried by asperities \\
\hline $\begin{array}{l}P e \\
P s i \\
\vec{r}\end{array}$ & $\begin{array}{l}\text { Peclet number } \\
\text { angle of entraining motion } \\
\text { mesh point position vector }\end{array}$ \\
\hline$r_{f r, p}, r_{f r, g}$ & moment arms for friction force \\
\hline$R_{p}, R_{g}$ & pinion and gear contact radii \\
\hline$R_{z x}$ & $\begin{array}{l}\text { equivalent radius of curvature along the minor axis of the contact } \\
\text { ellipse }\end{array}$ \\
\hline$R_{z y}$ & $\begin{array}{l}\text { equivalent radius of curvature along the major axis of the contact } \\
\text { ellipse }\end{array}$ \\
\hline$S_{0}$ & parameter in Houpert's equation \\
\hline 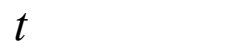 & time \\
\hline$T_{p}, T_{g}$ & externally applied torques to the pinion and gear \\
\hline$T_{f r, p}, T_{f r, g}$ & frictional moments at pinion and gear \\
\hline $\begin{array}{l}U \\
v_{s}\end{array}$ & $\begin{array}{l}\text { speed of entraining motion } \\
\text { surface velocity }\end{array}$ \\
\hline$W$ & dynamic mesh force \\
\hline $\begin{array}{l}X, X^{*} \\
x \\
Z \\
Z\end{array}$ & $\begin{array}{l}\text { dimensionless parameters expressing rise in lubricant film temperature } \\
\text { dynamic transmission error } \\
\text { direction across the film thickness } \\
\text { pressure exponent in Houpert's equation }\end{array}$ \\
\hline $\begin{array}{l}a^{*} \\
\alpha^{\prime}\end{array}$ & $\begin{array}{l}\text { pressure-viscosity coefficient } \\
\text { lubricant's coefficient of thermal expansion }\end{array}$ \\
\hline$\beta^{*}$ & $\begin{array}{l}\text { temperature-viscosity coefficient } \\
\text { shear rate }\end{array}$ \\
\hline
\end{tabular}




$\begin{array}{ll}\Delta U & \text { sliding velocity } \\ \Delta U^{*} & \text { dimensionless sliding velocity } \\ \Delta \varphi_{0} & \text { static angular transmission error under no load } \\ \varepsilon & \text { gear pair contact ratio } \\ \zeta & \text { asperity density per unit area } \\ \eta & \text { dynamic viscosity } \\ \eta_{0} & \text { dynamic viscosity at atmospheric pressure and inlet temperature } \\ \eta_{e} & \text { effective viscosity } \\ \theta & \text { lubricant temperature } \\ \theta_{0} & \text { bulk oil temperature } \\ \theta_{e} & \text { effective lubricant temperature } \\ \theta_{s 1}, \theta_{s 2} & \text { contact temperature of pinion and gear surfaces } \\ \kappa & \text { average asperity tip radius } \\ \mu & \text { coefficient of friction } \\ \vec{\xi} & \text { unit vector along the sliding direction } \\ \rho & \text { lubricant density } \\ \sigma & \text { composite surface roughness Ra } \\ \sigma_{r m s} & \text { RMS value of surface roughness } \\ \tau & \text { shear stress } \\ \tau_{0} & \text { Eyring shear stress of the lubricant oil } \\ \tau & \text { product of viscosity multiplied by the shear rate } \\ \varphi_{p}, \varphi_{g} & \text { pinion and gear angle of rotation } \\ \psi & \text { lubricant side leakage parameter } \\ \vec{\omega}_{p} & \text { pinion angular velocity } \\ \omega_{m e s h} & \text { meshing frequency } \\ \omega_{n} & \text { gear pair natural frequency } \\ & \end{array}$

\section{References}

[1]- Ozguven, H.N. and Houser, D.R. (1988), Mathematical models used in gear dynamics-A review, Journal of Sound and Vibration (1988) 121(3), 383-411

[2]- Ozguven, H.N. and Houser, D.R. (1988), Dynamic analysis of high speed gears by using loaded static transmission error, Journal of Sound and Vibration, 151(1), 71-83

[3]- Kahraman A. and Singh, R. (1990), Non-linear dynamics of a spur gear pair, Journal of Sound and Vibration, 142(1), pp.49-75

[4]- Kahraman A. and Singh, R. (1991), Interactions between the time varying mesh stiffness and clearance non-linearities in a geared system, Journal of Sound and Vibration, 146 (1), pp.135-156

[5]- Blankenship and G.W., Kahraman, A. (1995), Steady state forced response of a mechanical oscillator with combined parametric excitation and clearance type nonlinearity, Journal of Sound and Vibration, 185 (5), pp.743-765 
[6]- Blankenship, G.W. and Singh, R.S. (1995), Dynamic force transmissibility in helical gear pairs, Mech. Mash. Theory 30 (3), pp.323-339

[7]- Theodossiades, S. and Natsiavas, S. (2000), Non-linear dynamics of gear-pair systems with periodic stiffness and backlash, Journal of Sound and Vibration, 229(2), pp.287-310

[8]- Parker, R.G., Vijayakar, S.M. and Imajo T. (2000), Non linear dynamic response of a spur gear pair: Modelling and experimental comparisons, Journal of Sound and Vibration, 237(3), pp. 435-455

[9]- Quinlong M. and Kahraman A. (2005), Period-one motions of as mechanical oscillator with periodically time-varying, piecewise-nonlinear stiffness, Journal of Sound and Vibration, 284, pp.893-914

[10]- Bonori, G. and Pellicano, F. (2007), Non-smooth dynamics of spur gears with manufacturing errors, Journal of Sound and Vibration, 306, pp.271-283

[11]- Kiyono S., Fuji Y. and Suzuki Y. (1981), Analysis of vibrations of bevel gears, Bulletins of JSME 24, pp.441-446

[12]- Donley, M.G., Lim, T.C., and Steyer, G.C. (1992), Dynamic analysis of automotive gearing systems, Journal of passenger cars, 101 (6), pp.77-87

[13]- Cheng, Y. and Lim, T.C. (2001), Vibration analysis of hypoid transmission applying an exact geometry based gear mesh theory, Journal of Sound and Vibration, 240(3), pp. 519-543

[14]- Cheng, Y and Lim, T.C. (2003), Dynamics of hypoid gear transmission with non-linear time-varying mesh characteristics, Trans. ASME, Journal of Mechanical Design 125, pp.373-382.

[15]- Wang, J., Lim, T.C. and Li, M. (2007), Dynamics of a hypoid gear pair considering the effects of time-varying mesh parameters and backlash nonlinearity, Journal of Sound and Vibration, 229(2), pp.287-310.

[16]- Snidle, R.W. and Evans, H.P. (1997), Elastohydrodynamic of gears, in Dowson, D. et al (eds.) Elastohydrodynamics-'96: Fundamentals and Applications in Lubrication and Traction, Trib. Series 32, Elsevier Science, The Netherlands

[17]- Gohar, R. (2001) Elastohydrodynamics, Imperial College Press, London.

[18]- De la Cruz, M., Theodossiades, S. and Rahnejat, H (2010). An investigation of manual transmission drive rattle, Proc. IMechE, J. Multi-body Dynamics, 224, pp. 167-181

[19]- Vaishya, M. and Singh, R. (2001), Analysis of periodically varying gear mesh systems with Coulomb friction using Floquet theory, Journal of Sound and Vibration, 243 (3), pp.525-545

[20]- Vaishya, M. and Singh, R. (2001), Sliding friction-induced non-linearity and parametric effects in gear dynamics, Journal of Sound and Vibration, 248(4), 671694

[21]- Vaishya, M. and Singh, R. (2003), Strategies for modelling friction in gear dynamics, Trans. ASME, Journal of Mechanical Design, 125, pp. 383-393

[22]- Floquet, G. (1883), Sur les équations différentielles linéaires à coefficients périodiques, Ann. École Norm. Sup., 12: pp. 47-88.

[23]- He, S., Gunda, R. and Singh, R. (2007), Effect of sliding friction on the dynamics of spur gear pair with realistic time-varying stiffness, Journal of Sound and Vibration, 301, pp.927-949

[24]- Velex, P. and Cahouet, V. (2000), Experimental and numerical investigations on the influence of tooth friction in spur and helical gear dynamics, Trans. ASME, Journal of Mechanical Design, 122, pp. 515-522 
[25]- Velex, P. and Sainsot P. (2002), An analytical study of tooth friction excitations in errorless spur and helical gears, Mechanism and Machine Theory, 37, pp.641-658 [26]- Kar, C. and Mohanty, A.R. (2007), An algorithm for determination of timevarying frictional force and torque in a helical gear system, Mechanism and Machine Theory, 42, pp. 482-496

[27]- He, S., Gunda, R. and Singh, R. (2007), Inclusion of sliding friction in contact dynamics model for helical gears, Trans. ASME, Journal of Mechanical Design, 129, pp.48-57

[28]- De la Cruz, M., Theodossiades, S., Rahnejat, H. and Kelly, P. (2009), Numerical and experimental analysis of manual transmissions- Gear rattle, $S A E$, Pap. No. 2009-01-0328.

[29]- Gohar, R. and Rahnejat, H. (2008), Fundamentals of Tribology, Imperial College Press, London.

[30]- Grubin, A. N. (1949), Contact stresses in toothed gears and worm gears, Book 30 CSRI for Technology and Mechanical Engineering, Moscow, DSRI Trans., 337.

[31]- Rahnejat, H. (1984), The influence of vibration on the oil film in elastohydrodynamic contacts, PhD Thesis, Imperial College, London.

[32]- Rahnejat, H. (1985), Computational modelling of problems in contact dynamics, Engineering analysis, 2 (4), pp.192-197.

[33]- Mehdigoli, H., Rahnejat, H. and Gohar, R. (1990), Vibration response of wavy surfaced disc in elastohydrodynamic rolling contact, Wear, 130, pp. 1-15.

[34] Johnson, K.L. and Gray, G. G. (1975), Development of corrugations on surfaces in rolling contact, Proc. IMechE, J. Mech. Engng. Sci., 189, pp. 567-580

[35]- Li, S. and Kahraman, A. (2010), A transient mixed elastohydrodynamic lubrication model for spur gear pairs, Trans. ASME, Journal of tribology, 132(1), 9 pp.

[36]- Xu, H. and Kahraman, A. (2007), Prediction of friction-related power losses of hypoid gear pairs, Proc, IMechE, J. Multi-body Dynamics, 221, pp. 387-400

[37]- Holmes, M.J.A., Evans, H.P., Hughes, T.G. and Snidle, R.W. (2003), Transient elastohydrodynamic point contact analysis using a new coupled differential deflection method, Part 1: theory and validation, Proc. IMechE, J. Engng. Tribology, 217, pp.289-303

[38]- Holmes, M.J.A., Evans, H.P., Hughes, T.G. and Snidle, R.W. (2003), Transient elastohydrodynamic point contact analysis using a new coupled differential deflection method, Part 2: results, Proc. IMechE, J. Engng. Trib., 217, pp.305-321

[39]- Holmes, M.J.A., Evans, H.P. and Snidle, R.W. (2005), Analysis of mixed lubrication effects in simulated gear tooth contacts, Trans. ASME, Journal of Tribology, 127, pp. 61-69

[40]- Handschuh, R.F. and Kircher, T.P., (1996), A Method for Thermal Analysis of Spiral Bevel Gears, Trans. ASME, Journal of Mechanical Design, 118, pp.580-585

[41]- Greenwood, J.A. and Tripp (1970-71), The contact of two nominally flat rough surfaces, Proc. IMechE, J. Mech. Engng. Sci., 185-186, pp. 625-634

[42]- Vijayakar, S. 1998, Tooth Contact Analysis Software: CALYX, Advanced Numerical Solutions, Hilliard, $\mathrm{OH}$

[43]- Stadtfeld, H. 1993, Handbook of bevel and hypoid gears, Rochester Institute of Technology, New York

[44]- Eyring, H. 1936 Viscosity, plasticity and diffusion as examples of reaction rates, J. Chem. Phys., 4, p.283

[45]- Johnson, K.L. and Greenwood, J.A. 1980, Thermal Analysis of an Eyring fluid in Elastohydrodynamic traction, Wear 61 (1980), pp.353-374 
[46]- Houpert, L. 1985 New results of traction force calculations in elastohydrodynamic contacts, Trans. ASME, J. Lubn. Tech., 107, pp. 241-248.

[47]- Teodorescu M., Taraza D., and Henein N.A. 2003, Simplified elastohydrodynamic friction model of the cam-tappet contact, SAE Trans., Pap. No. 010985

[48]- Theodossiades, S., Tangasawi, O. and Rahnejat, H. 2007, Gear teeth impacts in hydrodynamic conjunctions promoting idle gear rattle, Journal of Sound and Vibration, 303 (2007), pp.632-658

[49]- Townsend, D.P. 1991, Dudleys Gear Handbook, McGraw-Hill, USA

[50]- Gosselin, G., Guertin T., Remond, D., and Jean, Y. 2000, Simulation and experimental measurement of the transmission error of real hypoid gears under load, Journal of Mechanical Design, 122, pp.109-122

[51]- Borner, J. and Houser, D., 1996, Friction and Bending Moments as Gear Noise Excitations, SAE paper 961816

[52]- Rahnejat, H., Multi-body dynamics: vehicles, machines and mechanisms, Professional Engng. Publishing (UK) and SAE (USA), 1998.

[53]- Evans, C.R. and Johnson, K.L. 1986, The rheological properties of elastohydrodynamic lubricants, Proc.Instn.Mech.Engrs Vol.100, pp.303-312

[54]- Lida, H., Tamura, A., and Yamada, Y., 1985, Vibrational characteristics of Friction between gear teeth, JSME, 28 (241), pp.1512-1519

\section{FIGURE CAPTIONS}

Figure 1: The hypoid gear pair mesh model

Figure 2: Free body diagram of the hypoid gear pair

Figure 3: Coordinate systems used in TCA

Figure 4: Geometric and kinematic properties at contact ellipse

Figure 5: Computational flowchart

Figure 6: Dimensionless mesh parameters with respect to pinion angular rotation: (a) Mesh Stiffness $\hat{k}_{m}$, (b) Pinion contact radius $\hat{R}_{p}$, (c) Gear contact radius $\hat{R}_{g}$. $\longrightarrow T_{p}=20 \mathrm{Nm},----T_{p}=50 \mathrm{Nm}, \cdots \cdots \cdots \cdots \cdot T_{p}=100 \mathrm{Nm},-\cdot-\cdot-T_{p}=250 \mathrm{Nm}$

Figure 7: Static transmission error during a complete meshing cycle

Figure 8: (a) Comparison of the dynamic transmission error amplitude variation for single and two DOF systems and dynamic response of the two DOF system at (b) $\omega_{\text {mesh }}=0.65 \omega_{n}$

Figure 9: Time histories of the dynamic transmission error when $\omega_{\text {mesh }}=0.3 \omega_{n} ;(a)$ general view (b) enhanced view formulation) 
Figure 10: FFT spectra of the dynamic transmission error when $\omega_{\text {mesh }}=0.3 \omega_{n} ;(a)$ single DOF (b) two DOF system

Figure 11: Time histories of the dynamic transmission error when $\omega_{\text {mesh }}=\omega_{n}$; (a) general view (b) enhanced view formulation)

single DOF - reduced order system (old formulation), double DOF (current

Figure 12: FFT spectra of the dynamic transmission error when $\omega_{\text {mesh }}=\omega_{n} ;(\mathrm{a})$ single DOF (b) two DOF system

Figure 13: Time histories of the dynamic transmission error for constant contact radii when (a) $\omega_{\text {mesh }}=0.3 \omega_{n}$, (b) $\omega_{\text {mesh }}=\omega_{n}$

— single DOF - reduced order system (old formulation), constant radii

Figure 14: FFT spectra of the dynamic transmission error for constant contact radii when (a) $\omega_{\text {mesh }}=0.3 \omega_{n}$, (b) $\omega_{\text {mesh }}=\omega_{n}$

Figure 15: Representation of a meshing cycle inside a traction map for a high viscosity mineral oil $\left(\omega_{\text {mesh }}=0.3 \omega_{n}\right)$ (after Evans and Johnson [53])

Figure 16: Time histories of the dynamic transmission for $\omega_{\text {mesh }}=0.3 \omega_{n}:$ (a) general view, (b) enhanced view

Dry conditions, Lubricated conditions

Figure 17: Time histories of the dynamic transmission for $\omega_{m e s h}=\omega_{n}:$ (a) general view, (b) enhanced view

Dry conditions, Lubricated conditions

Figure 18: Teeth contact properties $\left(\omega_{\text {mesh }}=0.3 \omega_{n}\right.$, composite surface roughness $\sigma=0.5 \mu \mathrm{m}$, lubricant inlet temperature $40^{\circ} \mathrm{C}$ );
(a) $\widehat{V}_{e},(\mathrm{~b})$ $\hat{\eta},(\mathrm{c})$ $\widehat{W}$, $\hat{h}$,
(d) $\hat{A},(\mathrm{e})$ $\hat{F}_{f r, b}$ $\hat{F}_{f r, v},(\mathrm{f})$ $\widehat{T}_{f r, p}$ $\mu$

Figure 19: (a) Traction curve and (b) viscosity plot $\left(\omega_{\text {mesh }}=0.3 \omega_{n}\right.$, surface roughness $\mathrm{S}_{\mathrm{rms}}=0.5 \mu \mathrm{m}$, lubricant inlet temperature $40^{\circ} \mathrm{C}$ )

Figure 20: Teeth contact properties $\left(\omega_{\text {mesh }}=\omega_{n}\right.$, composite surface roughness $\sigma=$ $0.5 \mu \mathrm{m}$, lubricant inlet temperature $40^{\circ} \mathrm{C}$ )
(a) $-\widehat{R}_{z x}$ $\widehat{V}_{e},(\mathrm{~b})-\widehat{T}$, $\hat{\eta},(\mathrm{c})$ $\widehat{W}$, $\hat{h}$,
(d)- $\frac{\Delta \hat{U}}{\Delta \hat{h}}$,
$\hat{A},(\mathrm{e})$
$\widehat{F}_{f r, b}$,
$\hat{F}_{f r, v},(\mathbf{f})$ $\widehat{T}_{f r, p}$, $\mu$

Figure 21: Contact properties $\left(\omega_{\text {mesh }}=0.3 \omega_{n}\right.$, composite surface roughness $\sigma=0.5$ $\mu \mathrm{m}$, lubricant inlet temperature $100^{\circ} \mathrm{C}$ )
(a)
$\widehat{T}$
$\hat{\eta},(\mathrm{b})-\frac{\Delta \hat{U}}{\Delta \hat{h}}$
$\widehat{h},(\mathrm{c})$
$\hat{F}_{f r, b}$ $\widehat{F}_{f r, v}$, 
(d) $\longrightarrow \widehat{T}_{f r, p}, \ldots \ldots \ldots \ldots$ 
Table 1: Gear pair parameters and machine/cutter settings (Gleason face hobbed gear set)

\begin{tabular}{ll}
\hline Pinion parameters: & \\
\hline Number of pinion teeth & 13 \\
Pinion face width $(\mathrm{mm})$ & 33.851 \\
Pinion face angle $(\mathrm{deg})$ & 29.056 \\
Pinion pitch angle $(\mathrm{deg})$ & 29.056 \\
Pinion root angle $(\mathrm{deg})$ & 29.056 \\
Pinion spiral angle $(\mathrm{deg})$ & 45.989 \\
Pinion pitch apex $(\mathrm{mm})$ & -9.085 \\
Pinion face apex $(\mathrm{mm})$ & 1.368 \\
Pinion Outer cone distance $(\mathrm{mm})$ & 83.084 \\
Pinion offset $(\mathrm{mm})$ & 24.0000028 \\
Pinion hand & Right
\end{tabular}

\begin{tabular}{ll}
\hline Gear parameters: & \\
\hline Number of gear teeth & 36 \\
Gear face width (mm) & 29.999 \\
Gear face angle (deg) & 59.653 \\
Gear pitch angle (deg) & 59.653 \\
Gear root angle (deg) & 59.653 \\
Gear spiral angle (deg) & 27.601 \\
Gear pitch apex (mm) & 8.987 \\
Gear face apex (mm) & 10.948 \\
Gear Outer cone distance (mm) & 95.598 \\
Gear offset (mm) & 24 \\
& \\
\hline Pinion machine and cutter parameters: & \\
\hline Inside cutter blade angle (IB) (deg) & 21.529 \\
Outside cutter blade angle (OB) (deg) & 16.743 \\
Machine center to back (mm) & -0.288 \\
Basic swivel angle (deg) & -32.865 \\
Basic cradle angle (deg) & 64.433 \\
Tilt angle & 31.736 \\
Sliding base (mm) & 20.647 \\
Ratio of roll & 2.762 \\
Blank offset (mm) & 23.908 \\
Machine root angle (deg) & 0.202 \\
Cutter point radius (mm) & 63.743 \\
Radial setting (mm) & 86.983 \\
\end{tabular}

\section{Gear machine and cutter parameters:}

\begin{tabular}{ll}
\hline Machine root angle (deg) & 59.653 \\
Machine center to back (mm) & 7.026 \\
Horizontal setting (mm) & 66.650 \\
Vertical setting (mm) & 62.642 \\
Inside cutter blade angle (deg) & 22.436 \\
Outside cutter blade angle (deg) & 15.815 \\
Cutter point radius (mm) & 64.185
\end{tabular}


Table 2: Lubricant properties

\begin{tabular}{|l|l|}
\hline Kinematic viscosity at $100^{0} \mathrm{C}(\mathrm{cSt})$ & 16.7 \\
\hline Kinematic viscosity at $40^{0} \mathrm{C}(\mathrm{cSt})$ & 109.1 \\
\hline Density $\left(\mathrm{kg} / \mathrm{m}^{3}\right)$ & 870 \\
\hline Thermal conductivity at $100^{0} \mathrm{C}(\mathrm{W} / \mathrm{mK})$ & 0.1077 \\
\hline Thermal conductivity at $40^{0} \mathrm{C}(\mathrm{W} / \mathrm{mK})$ & 0.1121 \\
\hline Pressure viscosity coefficient $\left(\mathrm{Pa}^{-1}\right)$ & $14.4^{*} 10^{-9}$ \\
\hline
\end{tabular}

